\author{
UNIVERSIDADE DE SÃO PAULO \\ ESCOLA DE ENFERMAGEM DE RIBEIRÃO PRETO
}

DIEGO OLIVEIRA MIRANDA

CORRELAÇÕES ENTRE PRODUÇÃO DE CITOCINAS, DEPRESSÃO E ANSIEDADE EM PACIENTES COM CÂNCER COLORRETAL EM DIFERENTES ESTÁGIOS DA TERAPIA ANTITUMORAL.

RIBEIRÃO PRETO 2014 


\section{CORRELAÇÕES ENTRE PRODUÇÃO DE CITOCINAS, DEPRESSÃO E ANSIEDADE EM PACIENTES COM CÂNCER COLORRETAL EM DIFERENTES ESTÁGIOS DA TERAPIA ANTITUMORAL.}

Tese apresentada à Escola de Enfermagem de Ribeirão Preto da Universidade de São Paulo para obtenção do título de Doutor em Ciências, Programa de Pós-Graduação Enfermagem em Saúde Pública.

Linha de pesquisa: Genômica e Imunobiologia aplicadas à Saúde Pública.

Orientadora: Prof ${ }^{a}$. Dr ${ }^{\mathrm{a}}$. Gabriela Silva Bisson

RIBEIRÃO PRETO 
Autorizo a reprodução e divulgação total ou parcial deste trabalho, por qualquer meio convencional ou eletrônico, para fins de estudo e pesquisa, desde que citada a fonte.

Miranda, Diego Oliveira

Correlações entre produção de citocinas, depressão e ansiedade em pacientes com câncer colorretal em diferentes estágios da terapia antitumoral. Ribeirão Preto, 2014.

71 p.: il.; $30 \mathrm{~cm}$

Tese de Doutorado, apresentada à Escola de Enfermagem de Ribeirão Preto/USP. Área de concentração: Saúde Pública.

Orientadora: Bisson, Gabriela Silva

1. Ansiedade. 2. Depressão. 3. Citocinas. 4. Câncer colorretal. 


\section{FOLHA DE APROVAÇÃO}

\section{Diego Oliveira Miranda}

“Correlações entre produção de citocinas, depressão e ansiedade em pacientes com câncer colorretal em diferentes estágios da terapia antitumoral”.

Tese de Doutorado apresentada a Escola de Enfermagem de Ribeirão Preto da Universidade de São Paulo para obtenção do Título de Doutor em Ciências, Programa de Pós-Graduação Enfermagem Saúde Pública.

Orientadora: $\operatorname{Prof}^{\mathrm{a}}$. Dr ${ }^{\mathrm{a}}$. Gabriela Silva Bisson

Aprovado em:

Banca Examinadora

$\operatorname{Prof}(a) \cdot \operatorname{Dr}(a)$ Instituição:

Julgamento: Assinatura:

Prof(a). Dr(a). Instituição:

Julgamento: Assinatura:

Prof(a). Dr(a). Instituição:

Julgamento: Assinatura: 


\section{DEDICATÓRIA}

À minha mãe, Silene, minha irmã, Thamy, e minha tia, Rosângela, pela dedicação incondicional e estímulo em todos esses anos.

À Profa. Dra. Gabriela Silva Bisson, pela orientação no desenvolvimento deste trabalho; pelo direcionamento e pelos ensinamentos que contribuíram para meu crescimento científico e profissional. 


\section{AGRADECIMENTOS}

À Deus, pela oportunidade de realizar mais um projeto na minha vida.

Aos pacientes, cuja confiança em participar de um projeto de pesquisa tornou possível à realização deste estudo.

À toda minha família pelo incentivo e apoio a cada nova etapa.

Ao grande amigo Lucas Ribeiro de Azevedo, cuja participação foi essencial durante as etapas deste estudo, dos cálculos aos experimentos, das discussões às conversas amigas.

Às amigas do LGBIO: Jéssica, Nádia, Tais, Elen, Lauren, Claudia, Michelle, e às Profas. Dras. Beatriz Rossetti Ferreira e Milena Flória-Santos. Desde o primeiro contato, me acolheram com muito carinho e, de todas as formas, 6uscaram ajudar. Agradeço pelo apoio científico.

Aे Professora Dra. Fernanda Maris Peria, por toda atenção, sabedoria e direcionamento que contribuíram para a realização deste estudo.

Aos funcionários da Central de Quimioterapia HCFMRP/USP pelo auxílio nos momentos necessários.

A todos os professores do programa de Saúde Pública, assim como de outros programas, por partilharem de seu conhecimento e experiência.

À Shirley, secretária do Departamento Materno Infantil e Saúde Pública, pelo auxílio em todas as questões burocráticas da pós-graduação, com seu interesse genuíno em ajudar.

À FAPESP, pela bolsa de doutorado concedida e à Pró-Reitoria de Pesquisa, pelo apoio financeiro ao laboratório,.

À todos que, de alguma forma contribuíram para a realização deste trabalho e que fizeram destes anos em Ribeirão Preto um tempo de grande aprendizado. Muito obrigado! 
“A percepção do desconhecido é a mais fascinante das experiências. O homem que não tem os olhos abertos para o misterioso passará pela vida sem ver nada”.

Al6ert Einstein 


\section{RESUMO}

MIRANDA, D. O. Correlações entre produção de citocinas, depressão e ansiedade em pacientes com câncer colorretal em diferentes estágios da terapia antitumoral. 2014. 71 f. Tese (Doutorado) - Escola de Enfermagem de Ribeirão Preto, Universidade de São Paulo, Ribeirão Preto, 2014.

O presente estudo teve como objetivo investigar se existe uma correlação entre ansiedade, depressão e níveis séricos de citocinas de pacientes com câncer colorretal em diferentes estágios da terapia antitumoral. Para tanto, utilizamos um total de 100 indivíduos, divididos em cinco grupos amostrais. Grupo 1. Voluntários saudáveis livres de qualquer doença psiquiátrica ou associada com alterações do sistema imune $(n=20)$; Grupo 2. Pacientes com diagnóstico de adenocarcinoma colorretal confirmado e que não foram submetidos à ressecção cirúrgica $(n=20)$; Grupo 3. Pacientes submetidos à ressecção cirúrgica e que não iniciaram a terapia adjuvante $(n=20)$; Grupo 4. Pacientes em tratamento quimioterápico há cerca de 3 meses, independentemente do esquema de quimioterapia aplicado $(n=20)$; Grupo 5. Pacientes que concluíram o esquema de quimioterapia adjuvante há cerca de 6 meses $(n=20)$. Depressão e ansiedade foram analisados utilizando Hospital Anxiety and Depression Scale (HADS) e níveis séricos de IL-1, IL-6, IL-8, IL-10, IL-12, TNF- $\alpha$, TGF- $\beta$ e Fractalcina foram mensurados por CBA. Níveis clinicamente relevantes de ansiedade e/ou depressão foram verificados em todos os pacientes com CCR em diferentes estágios da terapia antitumoral. Um padrão de produção semelhante foi observado para as citocinas pró-inflamatórias avaliadas. IL-1, IL-6, IL-8, TNF- $\alpha$ e Fractalcina foram encontradas em níveis elevados nos pacientes com CCR em estágio pré (G2) e pós-operatório (G3). Estes níveis foram, contudo, reduzidos durante (G4) e após (G5) o tratamento quimioterápico. Além disso, verificamos níveis diminuidos de IL-10 no soro dos pacientes dos grupos 2 e 3 (pré e pós-operatório). Ao analisarmos a correlação entre a pontuação HADS e os níveis séricos de citocinas, observamos uma associação positiva de ansiedade e/ou depressão com as concentrações de IL-1, IL-6, IL-8, TNF- $\alpha$ e Fractalcina e negativa com IL-10 em pacientes nos diferentes estágios da terapia antitumoral. Estes resultados indicam haver uma importante correlação entre os níveis séricos de citocinas pró-inflamatórias, ansiedade e depressão em pacientes com câncer colorretal, sugerindo que tais citocinas estão envolvidas na patofisiologia dessas comorbidades.

Palavras-chave: Ansiedade, depressão, citocinas, câncer colorretal. 


\begin{abstract}
MIRANDA, D. O. Correlation between cytokines, depression, and anxiety in colorectal cancer patients in different stages of the antitumor therapy. 2014. $71 \mathrm{f}$. Tese (Doutorado) - Escola de Enfermagem de Ribeirão Preto, Universidade de São Paulo, Ribeirão Preto, 2014.
\end{abstract}

This study aimed to investigate whether there is a correlation between anxiety, depression and serum cytokine levels in colorectal cancer in different stages of the antitumor therapy. A sample of 100 subjects was divided in 5 groups. Group 1: Healthy volunteers free of any psychiatric or immune system disease $(n=20)$; Group 2: Patients with colorectal cancer who did not undergo surgical resection $(n=20)$; Group 3: Patients who underwent surgical resection and who did not start adjuvant therapy $(n=20)$; Group 4: Patients undergoing chemotherapy for about 3 months, regardless of chemotherapy protocols applied $(n=20)$; Group 5: Patients who have completed adjuvant chemotherapy regimen for about 6 months $(n=20)$. Depression and anxiety were analyzed using the Hospital Anxiety and Depression Scale (HADS), and serum levels of IL-1, IL-6, IL-8, IL-10, IL-12, TNF- $\alpha$, TGF- $\beta$, and Fractalkine were measured by CBA. Clinically relevant levels of anxiety and/or depression were found in all CRC patients in different stages of the antitumor therapy. A similar pattern of production was observed for proinflammatory cytokines. Elevated levels of IL-1, IL-6, IL8, TNF- $\alpha$, and Fractalkine were found in CRC patients in pre (G2) and postoperative (G3) stages. However, these levels were reduced during (G4) and after (G5) chemotherapy. Furthermore, we found decreased levels of IL-10 in serum of patients in CRC patients in pre and postoperative stages. By analyzing the correlation between HADS scores and serum cytokine levels, we observed a positive association of anxiety and/or depression with the concentrations of IL-1, IL-6, IL-8, TNF- $\alpha$, and Fractalkine, and negative with IL-10 in patients in different stages of the antitumor therapy. These results indicate an important link between serum levels of proinflammatory cytokines, anxiety and depression in CRC patients, suggesting that such cytokines are involved in the pathophysiology of these comorbidities.

Key words: Anxiety, depression, cytokines, colorectal cancer. 


\section{RESUMEN}

MIRANDA, D. O. Las correlaciones entre las citoquinas, la depresión y la ansiedad en los pacientes con cáncer colorrectal en diferentes etapas de la terapia antitumoral. 2014. 71 f. Tese (Doutorado) - Escola de Enfermagem de Ribeirão Preto, Universidade de São Paulo, Ribeirão Preto, 2014.

El presente estudio tuvo como objetivo investigar si existe una correlación entre los niveles de ansiedad, depresión y citocinas en suero en pacientes con cáncer colorrectal en diferentes etapas de la terapia antitumoral. Una muestra de 100 sujetos se dividió en 5 grupos. Grupo 1. Voluntarios sanos libre de cualquier enfermedad psiquiátrica o asociado con alteraciones del sistema inmunitario ( $\mathrm{n}=20$ ); Grupo 2. Los pacientes con diagnóstico confirmado de cáncer colorrectal y que no se sometió a resección quirúrgica $(n=20)$; Grupo 3. Pacientes fueron sometidos a resección quirúrgica y que no empezaron la terapia adyuvante $(n=20)$; Grupo 4. Pacientes sometidos a quimioterapia durante unos tres meses, independientemente de los régimen de quimioterapia utilizados $(n=20)$; Grupo 5. Pacientes que completaron el régimen de quimioterapia adyuvante durante 6 meses $(n=20)$. La depresión y la ansiedad fueron analizados utilizando el Hospital Anxiety and Depression Scale (HADS) y los niveles séricos de IL-1, IL-6, IL-8, IL-10, IL-12, TNF- $\alpha$, TGF- $\beta$ y Fractalkine se midieron por CBA. Se observaron niveles clínicamente relevantes de ansiedad y/o depresión en todos los pacientes con CCR en diferentes etapas de la terapia antitumoral. Un patrón similar se observó para la producción de citocinas proinflamatorias. IL-1, IL-6, IL-8, TNF- $\alpha$ y fractalquina se encontraron en niveles elevados en pacientes con CCR en la etapa pre $(\mathrm{G} 2)$ y postoperatoria (G3). Sin embargo, estos niveles se redujeron durante (G4) y después (G5) la quimioterapia. Además, hemos encontrado niveles disminuidos de IL-10 en el suero de los pacientes en los grupos 2 y 3 (pre y postoperatorio). Al analizar la correlación entre el puntaje HADS y los niveles séricos de citocinas, se observó una asociación positiva de la ansiedad y/o depresión con concentraciones de IL-1, IL-6, IL-8, TNF- $\alpha$ y Fractalquina y asociación negativa los niveles séricos de IL-10 en pacientes en diferentes etapas de la terapia antitumoral. Estos resultados indican un vínculo importante entre los niveles séricos de citocinas proinflamatorias, la ansiedad y la depresión en pacientes con cáncer colorrectal, lo que sugiere que las citoquinas están implicadas en la fisiopatología de estas comorbilidades.

Palabras clave: Ansiedad, depresión, citocinas, cáncer colorrectal. 


\section{LISTA DE FIGURAS}

Figura 1. Concentrações plasmáticas das citocinas IL-1beta, IL-6, IL-8, TNF-alfa, IL-10, IL-12, TGF-beta e Fractalcina................................................................. 41 


\section{LISTA DE QUADROS}

Quadro 1. Estadiamento clínico do câncer colorretal conforme AJCC 7 7 edição.............. 19 


\section{LISTA DE TABELAS}

Tabela 1. Características clínicas e demográficas dos participantes do estudo. 39

Tabela 2. Escore de ansiedade e depressão dos participantes do estudo. 40

Tabela 3. Correlações entre níveis séricos de citocinas e escores HADS 43 


\section{LISTA DE ABREVIATURA}

AJCC American Joint Committee on Cancer (Comitê Misto Americano sobre o Câncer)

CBA Cytometric Bead Array (Ensaio de citometria de microesferas)

CCR Câncer colorretal

CD4+ Linfócito auxiliar com grupamento de diferenciação 4 positivo

CD8+ Linfócito auxiliar com grupamento de diferenciação 8 positivo

CEA Carcinogenic embryonic antigen (Antígeno carcinoembrionário)

CEP Comitê de Ética em Pesquisa

CX3CL1 Fractalcina circulante

DP Desvio padrão

EERP Escola de Enfermagem de Ribeirão Preto

HADS Hospital Anxiety and Depression Scale (Escala hospitalar de ansiedade e depressão)

HCFMRP Hospital das Clínicas da Faculdade de Medicina de Ribeirão Preto

HHA Eixo hipotálamo-hipófise-adrenal

IL- Interleucina

INCA Instituto Nacional do Câncer

$\mathrm{NF}-\mathrm{Kb} \quad$ Factor nuclear kappa B (Fator nuclear kappa B)

NK Natural Killer cells (Células assassinas naturais)

PAs Pólipos adenomatosos 
QV Qualidade de vida

SNC Sistema nervoso central

STAT3 Signal transducer and activator of transcription 3 (Transdutor de sinal e ativador de transcrição 3)

TGF- $\beta \quad$ Transforming growth factor - beta (Fator de crescimento transformador)

Th1 Linfócito T CD4+ helper (auxiliar) subtipo 1

Th2 Linfócito T CD4+ helper (auxiliar) subtipo 2

TNF- $\alpha \quad$ Tumor Necrosis Factor - alfa (Fator de necrose tumoral)

TRP Triptofano

USP Universidade de São Paulo 


\section{SUMÁRIO}

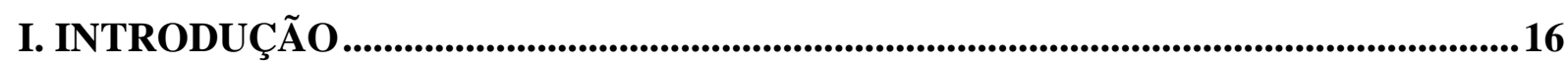

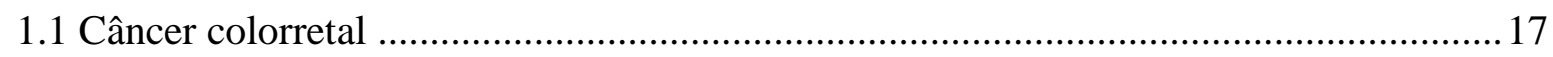

1.2 Depressão e ansiedade em pacientes com CCR …………………………………...2

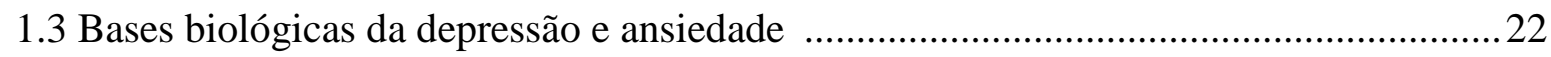

1.4 Instrumento de avaliação da depressão e ansiedade ………………………………......2

1.5 Sistema imunoinflamatório na depressão e ansiedade .................................................2

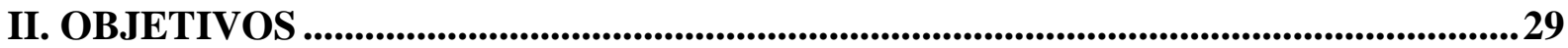

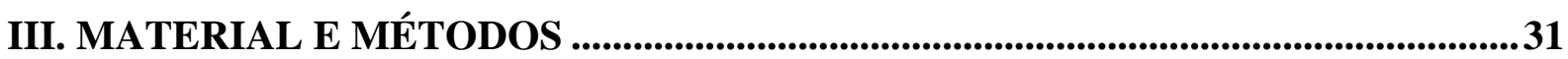

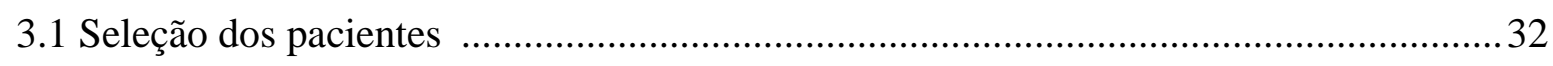

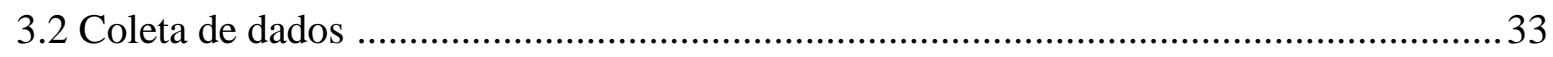

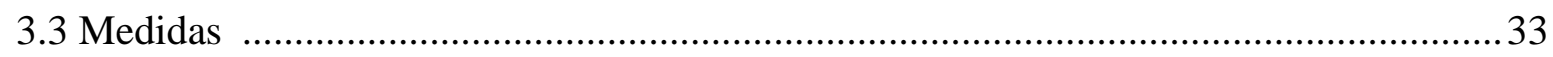

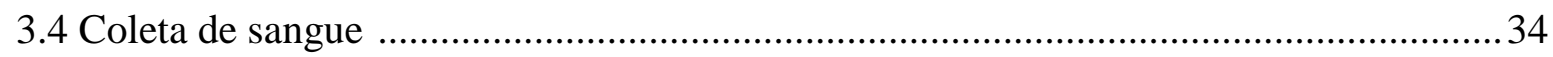

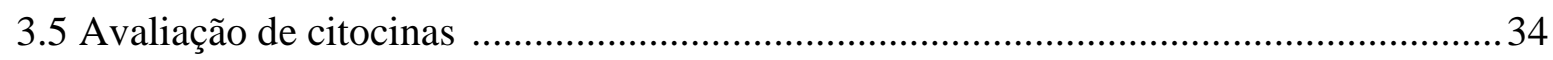

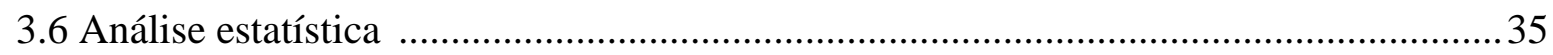

IV. RESULTADOS

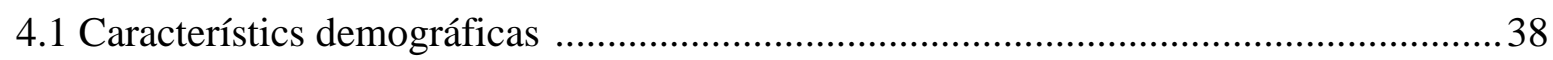

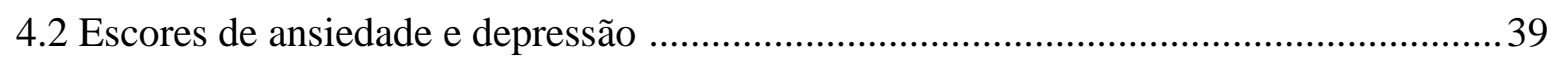

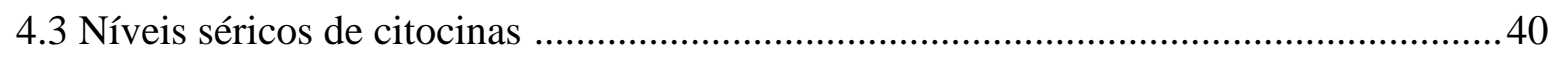

4.4 Correlações entre escores HADS e níveis de citocinas ..................................................42

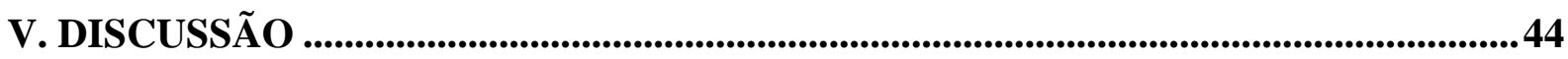

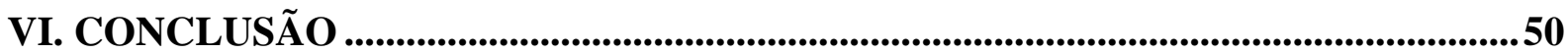

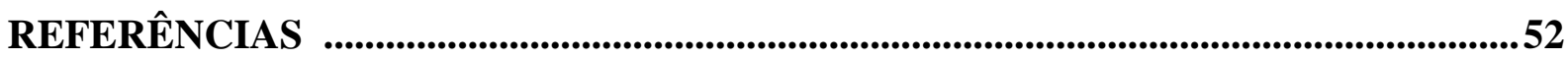

ANEXOS .................................................................................................................................68 


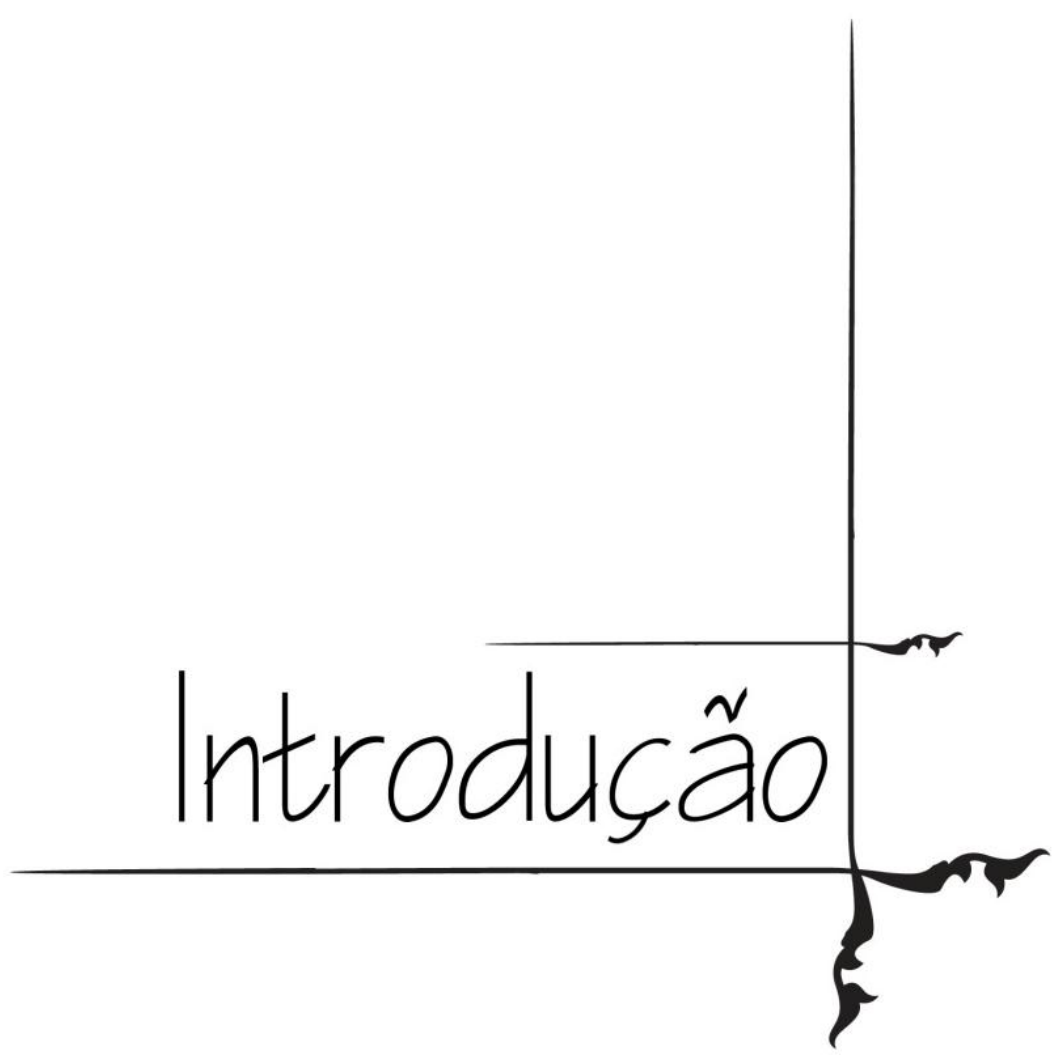




\section{INTRODUÇÃO}

\subsection{Câncer colorretal}

A incidência de neoplasias tem aumentado anualmente, sendo o câncer colorretal (CCR) o terceiro mais comum no mundo e a segunda causa de morte por câncer no ocidente (Ferlay et al., 2013). No Brasil, o Instituto Nacional do Câncer (INCA) estima que, em 2014, cerca de 17.000 mulheres serão afetadas pelo CCR, superando, pela primeira vez, o número de casos de câncer de colo do útero, atrás apenas de tumores de mama. Entre os homens, cerca de 15.000 novos casos são estimados, número superado apenas pelos tumores de pulmão e próstata (Brasil, 2013).

Dentre os principais fatores de risco, destacam-se a predisposição genética ao desenvolvimento de doenças crônicas do intestino, histórico familiar de CCR e idade superior a 50 anos, uma vez que tanto a incidência quanto a mortalidade aumentam com a idade. Além disso, uma dieta baseada em gordura animal com baixa ingestão de frutas, vegetais e cereais, o consumo excessivo de álcool, o tabagismo e o sedentarismo contribuem para o aparecimento da doença (Wilschut et al., 2010; Brasil, 2013). As doenças inflamatórias intestinais, como a colite ulcerativa e a doença de Crohn, também são fatores de risco importantes; nesse caso, o risco para o CCR aumenta proporcionalmente com a gravidade e o tempo de doença inflamatória (Ueno et al., 2010). Apesar disso, a maioria dos cânceres colorretais (cerca de 75\%) ocorre de forma esporádica, surgindo de mutações somáticas e evolução do clone celular tumoral (Brasil, 2013). 
O câncer colorretal pode se apresentar de maneira assintomática e sintomática. O diagnóstico em pacientes assintomáticos normalmente ocorre durante a realização de exames de rastreamento (pesquisa de sangue oculto, retosigmoidoscopia ou colonoscopia), recomendado para todos os pacientes acima dos 50 anos de idade (Lieberman, 2009). Os sintomas mais frequentes ao diagnóstico são a presença de dor abdominal, alteração do hábito intestinal e hematoquezia ou melena, entre outros (Walling et al., 2014).

A história natural dessa neoplasia propicia condições ideais à sua detecção precoce, pois apresenta uma transição de criptas normais a adenoma e, posteriormente a adenocarcinoma, durante um período de 10 a 20 anos, podendo chegar a 25 anos (Ogino et al., 2011). Evidências demonstram a redução da morbimortalidade associada à detecção precoce de lesões invasivas e precursoras de pólipos adenomatosos (PAs). Contudo, os sintomas podem não ser aparentes até o final do curso da doença e por essa razão o CCR é frequentemente diagnosticado em uma fase avançada (Tanaka, 2009).

O estadiamento é realizado por meio do exame físico, das tomografias de tórax, abdome e pelve e dosagem do antígeno carcinoembrionário (CEA). A determinação do correto estadiamento é fundamental para a definição do prognóstico e planejamento do tratamento.

O estadiamento do CCR segue o sistema TNM da American Joint Committee on Cancer (AJCC). O quadro 1 lista as classificações de T, N e M e o agrupamento em estadios (Edge et al., 2010; Gunderson et al., 2010). De forma resumida, no estadio 0, a doença está localizada somente na parte interna do cólon ou do reto, denominado carcinoma in situ; no estadio I, o tumor cresceu dentro da parte interna do cólon ou reto, mas não atravessou a parede do intestino; no estadio II, o tumor se estende mais profundamente dentro e na parede do cólon ou reto, mas as células cancerosas não chegaram aos gânglios linfáticos; no estadio 
III, o câncer se disseminou aos gânglios linfáticos próximos, mas não para outras partes do corpo e no estadio IV, já se disseminou para outras partes do corpo.

Quadro 1. Estadiamento clínico do câncer colorretal conforme AJCC 7a edição.

\begin{tabular}{|c|c|c|c|}
\hline Estadio & Tumor Primário & Linfonodos Regionais & Metástases \\
\hline 0 & Tis & No & M0 \\
\hline $\mathrm{I}$ & T1-T2 & No & M0 \\
\hline IIA & $\mathrm{T} 3$ & N0 & M0 \\
\hline IIB & $\mathrm{T} 4 \mathrm{a}$ & N0 & M0 \\
\hline IIC & $\mathrm{T} 4 \mathrm{~b}$ & N0 & M0 \\
\hline \multirow[t]{2}{*}{ IIIA } & T1-T2 & N1 & M0 \\
\hline & T1 & $\mathrm{N} 2 \mathrm{a}$ & M0 \\
\hline \multirow[t]{3}{*}{ IIIB } & T3-T4a & N1 & M0 \\
\hline & T2-T3 & $\mathrm{N} 2 \mathrm{a}$ & M0 \\
\hline & T1-T2 & $\mathrm{N} 2 \mathrm{~b}$ & M0 \\
\hline \multirow[t]{3}{*}{ IIIC } & T4a & $\mathrm{N} 2 \mathrm{a}$ & M0 \\
\hline & $\mathrm{T} 3-\mathrm{T} 4 \mathrm{~b}$ & $\mathrm{~N} 2 \mathrm{~b}$ & M0 \\
\hline & $\mathrm{T} 4 \mathrm{~b}$ & N1-N2 & M0 \\
\hline IVA & qqT & $\mathrm{qqN}$ & M1a \\
\hline IVB & qqT & $\mathrm{qqN}$ & M1b \\
\hline
\end{tabular}

Tis: doença em estágio inicial, denominado carcinoma in situ; T1: o tumor se desenvolveu através da muscular mucosa até a submucosa; T2: o tumor cresceu através da submucosa e se estende até a muscular própria; T3: o tumor cresceu através da muscular própria e nas camadas mais externas do cólon ou do reto; T4a: o tumor cresceu através da serosa, o revestimento externo dos intestinos. T4b: o tumor cresceu através da parede do cólon ou do reto ou invade os tecidos e órgãos próximos; N0: os linfonodos estão livres; N1: presença de células cancerosas em 1 a 3 gânglios linfáticos; N1a: presença de células cancerosas em 1 linfonodo; N1b: presença de células cancerosas de 2 a 3 linfonodos; N2: presença de células cancerosas em 4 ou mais linfonodos próximos; N2a: presença de células cancerosas de 4 a 6 gânglios linfáticos; N2b: presença de células cancerosas em mais de 7 linfonodos; M0: ausência de metástases à distância; M1a: a doença se disseminou para um órgão ou conjunto de linfonodos distantes; M1b: a doença se disseminou para mais de um órgão ou conjunto de linfonodos distantes ou se disseminou a partes distantes do peritônio. 
De acordo com o sistema de estadiamento AJCC (2010), o prognóstico do CCR varia de acordo com a extensão da doença no momento do diagnóstico; $74 \%$ dos pacientes sem metástase (estadio I), perante $6 \%$ dos que apresentam a doença metastática (estadio IV), têm uma sobrevida de 5 anos.

As modalidades terapêuticas disponíveis para o tratamento do CCR incluem a cirurgia, a quimioterapia e a radioterapia, sendo a maioria dos casos tratada cirurgicamente. Pacientes em estadio I a III são bons candidatos à ressecção cirúrgica com o objetivo de proporcionar cura, que dessa forma, é considerada a primeira opção de tratamento (Kordatou et al., 2014). Entretanto, sem tratamento adicional, aproximadamente $50 \%$ dos pacientes submetidos à ressecção cirúrgica apresentam recidivas e progressão da doença metastática (Medeiros et al., 2010). Assim, o uso de quimioterapia adjuvante é indicado nos pacientes em estadio III e, em pacientes estadio II com alto risco de recidiva, com o objetivo de erradicar células tumorais residuais após a cirurgia (Jorgensen et al., 2013; Schneider; Langner, 2014).

Vários estudos avaliaram o impacto de diferentes tratamentos na qualidade de vida do paciente portador de CCR (Schmidt et al., 2005; Pollack et al., 2006). O tratamento quimioterápico influencia diretamente os escores de dor, depressão, ansiedade e perda de funções cognitivas apresentados pelos pacientes (Nicolussi; Sawada, 2009). Segundo Andersen e colaboradores (1989), sintomas psicológicos tendem a diminuir com o passar do tempo e, com o término do tratamento, a maioria dos pacientes portadores de câncer tem seu padrão de humor normalizado. 


\subsection{Depressão e ansiedade em pacientes com CCR}

A importância de se avaliar as implicações do câncer, não somente em termos de sobrevida do paciente, mas também em termos de qualidade de vida durante e após o tratamento, está bem estabelecida (Moinpour et al., 2000; Dunn et al., 2003) e é atualmente, parte integrante dos fundamentos da Enfermagem Oncológica (Kusahara et al., 2008).

Pacientes com câncer colorretal apresentam alta prevalência de distúrbios psicológicos, sendo depressão e ansiedade consideradas as comorbidades psicopatológicas mais importantes nesses pacientes (Dunn et al., 2006). Medeiros e colaboradores (2010) verificaram que cerca de $38 \%$ dos portadores do CCR em tratamento quimioterápico manifestam depressão. Além disso, 40\% dos pacientes com recidiva da doença desenvolvem algum tipo de depressão e/ou ansiedade (Zabora et al., 2001). Depressão e ansiedade constituem, assim, importantes sintomas-alvo para intervenções psicossociais a serem realizadas por profissionais de saúde, incluindo enfermeiros (Alacacioglu et al., 2010).

A depressão e a ansiedade em pacientes com câncer frequentemente não é diagnosticada e, portanto, não tratada. As barreiras para o tratamento desses sintomas em pacientes com câncer podem decorrer da incerteza sobre o diagnóstico e o tratamento, além do tempo por vezes limitado para investigar questões emocionais e dos custos associados ao tratamento. A própria natureza da síndrome depressiva, que inclui sentimentos de desvalia e desespero, inibe a procura de cuidado e interfere na capacidade dos pacientes para avaliar a distorção emocional e cognitiva decorrente da depressão, muitas vezes atribuída ao câncer (Greenberg, 2004). A ocorrência de sofrimento psíquico grave entre pacientes com CCR interfere negativamente na adesão ao tratamento anti-neoplásico e na qualidade de vida desses sujeitos (Bottino et al., 2009; Carmack et al., 2011). Esta condição pode estar relacionada a 
vários fatores físicos, psicológicos, espirituais, sociais e/ou culturais, como a angústia do tratamento, o medo da morte e da recidiva da doença, além da alteração da imagem corporal e da sexualidade devido à presença de estoma (Alacacioglu et al., 2010; Medeiros et al., 2010). Cerca de $80 \%$ dos pacientes experienciam mudanças no estilo de vida e mais de $30 \%$ têm problemas com a sua vida sexual (Alacacioglu et al., 2010). A ocorrência de dor e de metástases também aumenta a prevalência de depressão e ansiedade em pacientes com câncer (Ciaramella; Poli, 2001).

\subsection{Bases biológicas da depressão e ansiedade}

Nas últimas quatro décadas, os transtornos depressivos têm sido explicados pela hipótese monoaminérgica, através da qual a depressão seria o resultado de uma diminuição dos níveis de aminas biogênicas no sistema nervoso central (SNC), em particular de serotonina, noradrenalina e/ou dopamina. Esta teoria é avigorada pelo conhecimento do mecanismo de ação dos antidepressivos, que se baseiam no aumento da disponibilidade desses neurotransmissores na fenda sináptica (Nishida et al., 2002; Ruhé et al., 2007).

A ansiedade patológica tem sido postulada como resultante de uma hiperatividade dos sistemas associados à ansiedade normal (Charney; Drevets, 2004). De acordo com o modelo proposto por Gray e McNaughton (2000), a ativação do sistema comportamental inibitório, cujos correlatos anatômicos são o hipotálamo e as estruturas próximas, levaria à inibição do comportamento motor, à hiperatividade autonômica e ao aumento do estado de alerta. Assim, a estimulação do SNC, com aumento da disponibilidade de serotonina no hipotálamo, estaria 
relacionada aos sintomas da ansiedade (Castillo et al., 2000; Gray; McNaughton, 2000; Charney; Drevets, 2004).

No entanto, apesar de muitos estudos, a etiologia da depressão e da ansiedade permanece incerta. Recentemente, outras hipóteses têm recebido destaque na descrição da etiologia da depressão e da ansiedade, envolvendo a participação dos sistemas imune e endócrino (Calil; Guerra, 2004; Castrén et al., 2007). O quadro depressivo é conhecido por ser acompanhado de ativação da resposta imunoinflamatória. As catecolaminas, liberadas pela estimulação do eixo neuroendócrino durante a depressão, modulam a atividade das células imunes, interferindo na proliferação de linfócitos e na produção de citocinas e anticorpos (Madden, 2003). Indivíduos com depressão apresentam aumento no número de leucócitos sanguíneos periféricos, elevação na concentração plasmática de proteínas de fase aguda, incremento da razão de células CD4+/CD8+, além de um aumento nos níveis sanguíneos de citocinas pró-inflamatórias, tais como IL-1, IL-6, IL-8 e TNF- $\alpha$ (Vismari et al., 2008). Tem sido proposto que o aumento na produção de citocinas pró-inflamatórias e um desbalanço na resposta Th1/Th2 podem desempenhar um papel relevante na fisiopatologia da ansiedade e da depressão.

De acordo com diferentes teorias, a ansiedade e a depressão são consideradas como um fenômeno psiconeuroimunológico (Vismari et al., 2008). Todas se fundamentam na ideia de que os sintomas observados na ansiedade e na depressão resultariam do aumento na produção de citocinas pró-inflamatórias, as quais atuariam como neuromoduladores, mediando os aspectos neuroquímicos, neuroendócrinos e comportamentais dos transtornos ansiosos e depressivos (Yirmiya et al., 2000; Leonard, 2007).

O eixo neuroendócrino mais bem estudado nesses transtornos psiquiátricos é o hipotálamo-hipófise-adrenal (HHA) e sua conexão com estruturas do sistema límbico, como o hipocampo e a amígdala. Uma vez que este eixo desempenha um importante papel no 
desenvolvimento e na expressão de inúmeros comportamentos, suas disfunções podem estar implicadas na fisiopatologia da depressão e da ansiedade (Checkley, 1996). O eixo HHA desempenha um papel fundamental na resposta aos estímulos externos e internos (dentre eles os estressores psicológicos) e leva ao aumento da concentração sanguínea de cortisol em situações de estresse, influenciando o metabolismo celular e gerando a mobilização dos substratos energéticos necessários para a produção de respostas fisiológicas adaptativas à presença dos agentes estressores (Pacák; Palkovits, 2001; González; Escobar, 2002). Citocinas pró-inflamatórias como IL-6 e TNF- $\alpha$ são conhecidas por sua capacidade de ativar o eixo HHA (Leonard, 2001). Evidências apontam que a hipersecreção de citocinas próinflamatórias levaria a um prejuízo na neurotransmissão noradrenérgica e serotonérgica cerebral, o que resultaria em alguns dos sintomas da depressão (Leonard, 2001; Nishida et al., 2002).

\subsection{Instrumento de avaliação da depressão e ansiedade}

Diversos autores enfatizam a predominância de aspectos psicológicos como os distúrbios do humor e de ansiedade nos pacientes com câncer (Moinpour et al., 2000; Dunn et al., 2003). A avaliação desses distúrbios é frequentemente realizada por meio de escalas não diagnósticas que mensuram apenas os sintomas clínicos (Matta; Moreira-Filho, 2003).

A Escala Hospitalar de Ansiedade e Depressão (Hospital Anxiety and Depression Scale, HADS) foi desenvolvida por Zigmond e Snaith em 1983 para identificar casos de transtornos de ansiedade e depressão entre os pacientes em clínicas hospitalares nãopsiquiátricas (Zigmond; Snaith, 1983). Dessa forma, a HADS possibilita avaliar 
separadamente a depressão e a ansiedade tanto em pacientes com outras doenças instaladas

como em indivíduos não considerados doentes (Ballenger et al., 2001). É formada por 14 questões, das quais sete relacionadas à ansiedade e sete à depressão (Zigmond; Snaith, 1983). O entrevistado atribui nota de zero a três para cada uma das perguntas, perfazendo totais que podem variar de 0 a 21 em cada subescala. Pontuação de oito ou mais, tanto na subescala de ansiedade quanto na de depressão, é sugestiva de transtorno de ansiedade e de depressão, respectivamente (Botega et al., 1998), embora a HADS não tenha como objetivo quantificar a gravidade do sintoma.

A escala possui como grande vantagem a ausência de sintomas confusos comuns entre doenças clínicas e depressão e ansiedade, como fadiga, perda do apetite e alterações do sono. Esse instrumento também pode avaliar sintomas subjetivos mais específicos para a depressão e ansiedade, demonstrando, no seu resultado final, a necessidade ou não do uso de outros métodos diagnósticos adequados para a identificação e a condução do tratamento (Botega et al., 1998).

\subsection{Sistema imunoinflamatório na depressão e ansiedade}

Inicialmente relacionadas como mediadores humorais de interações entre as células do sistema imunológico, as citocinas passaram a ser consideradas, mais recentemente, também como fatores essenciais para a interação entre o sistema imune e o sistema nervoso central (Wrona, 2006; Ren; Dubner, 2010). Células do sistema imune periférico são as principais produtoras de citocinas, as quais podem alcançar o cérebro através de regiões onde a barreira hematoencefálica está ausente, menos restritiva, ou comprometida. Além disso, citocinas 
podem ser liberadas por neurônios e células da glia no próprio SNC, como no hipotálamo, hipocampo, núcleos da base, entre outros locais. Está cada vez mais evidente que a produção de citocinas passa pelo controle tônico dos sistemas nervosos central e periférico, visto que as células imunes apresentam receptores para diversos neurotransmissores e a ativação dos mesmos modula a produção de citocinas (Muller; Ackenheil, 1998; Szelényi; Vizi, 2007).

Os membros desta grande e diversificada família de polipeptídeos de sinalização são classificados, tradicionalmente, como linfocinas (citocinas produzidas por linfócitos ativados, especialmente linfócitos $\mathrm{T}$ auxiliares), interleucinas (citocinas que agem como mediadores entre leucócitos), ou quimiocinas (citocinas quimiotáticas produzidas por diferentes tipos celulares, incluindo leucócitos) (Ransohoff; Benveniste, 2006; Janssen et al., 2010).

Apesar de suas atividades biológicas específicas variarem, duas categorias gerais de citocinas podem ser distinguidas, pró-inflamatórias e anti-inflamatórias. O primeiro grupo é composto por citocinas que estão envolvidas direta ou indiretamente nos processos inflamatórios. O outro grupo é composto por citocinas que são conhecidas por regularem a resposta imune pela diminuição da ativação celular e da produção de mediadores (pró) inflamatórios. Este grupo inclui a IL-4, IL-10 e TGF- $\beta$ (Schiepers et al., 2005).

Em indivíduos saudáveis, existe um equilíbrio entre citocinas pró- e anti-inflamatórias: por exemplo, IL1, IL-6, IL-8 e TNF- $\alpha$ medeiam a fase inicial do processo inflamatório, e, em seguida, ocorre a liberação de IL-10 e TGF- $\beta$, as quais exercem efeitos de imunoregulação e resolvem a inflamação (You et al., 2011). Assim, o sistema imunológico pode responder rapidamente a desafios e, posteriormente, retornar à homeostase (Dhabhar et al., 2009).

As citocinas desempenham um papel na patogênese de vários distúrbios, incluindo infecção, doenças auto-imunes, doenças neurodegenerativas (Ransohoff; Benveniste, 2006) e também estão implicadas na patogênese de inúmeras desordens neuropsiquiátricas (Capuron; Dantzer, 2003; Irwin; Miller, 2007). Na depressão e na ansiedade, ocorre uma ruptura do 
equilíbrio entre citocinas pró e anti-inflamatórias. Nesses quadros, os níveis de citocinas próinflamatórias como IL-1, IL-6, IL-8 e TNF- $\alpha$ estão frequentemente elevados, enquanto que os níveis de citocinas anti-inflamatórias como IL-10 e TGF- $\beta$ se encontram reduzidos (O'Brien et al., 2004; O'Brien et al., 2007; Dhabhar et al., 2009).

Os caminhos biológicos através dos quais as citocinas estão associadas a ansiedade e a depressão são mal compreendidos. Todavia, alguns mecanismos tem sido propostos, as citocinas pró-inflamatórias podem: (1) afetar o metabolismo da serotonina pela redução dos níveis de triptofano (TRP); (2) exercer um potente efeito direto sobre o eixo hipotálamohipófise-adrenal (Janssen et al., 2010).

Por sua vez, as quimiocinas, caracterizadas inicialmente por sua capacidade de recrutar leucócitos para sítios de inflamação, vêm ganhando destaque entre os moduladores da resposta dirigida a tumores (Reed et al., 2012; Zheng et al., 2013) e em processos neuropatológicos como depressão e ansiedade (Merendino et al., 2004; Stuart; Baune, 2014). A fractalcina (CX3CL1), único membro da família de quimiocinas CX3C, é uma quimiocina com receptor altamente seletivo para o marcador de superfície de linfócitos efetores citotóxicos, tais como as células NK e os linfócitos T citotóxicos, que expressam grandes quantidades de perforina e granzima (Umehara et al., 2004). No SNC, a fractalcina é constitutivamente expressa por neurônios saudáveis, e no sangue periférico e fluido sinovial, é expressa por monócitos durante as condições inflamatórias (Zujovic et al., 2001). Devido à sua influência no influxo de células do sistema imunológico na resposta antitumoral, foi identificada como um importante alvo de imunoterapia de tumores (Nelson; Muenchmeier, 2013) e tem sido sugerida como um fator prognóstico favorável na sobrevida de portadores de CCR (Ohta et al., 2005; Agalliu et al., 2013). Ao longo dos últimos anos, tem havido um interesse crescente no entendimento do papel da fractalcina em distúrbios do SNC. Em estudo prévio, a importância da fractalcina e seu receptor (CX3CR1) em distúrbios neurológicos foi 
avaliada utilizando um modelo animal em que o gene CX3CR1 foi substituído produzindo um defeito no receptor (Maggi et al., 2011). Usando este modelo animal, os estudos relataram que a ausência de CX3CR1 está associada a alterações neuropsiquiátricas, possivelmente devido à falta de regulação na ativação microglial pela fractalcina, levando a uma neuroinflamação crônica e distúrbios psiquiátricos (Corona et al., 2010; Ladecola; Anrather, 2011; Briones et al., 2014).

As evidências sugestivas de um papel das citocinas, especialmente IL-1, IL-6, IL-8, TNF- $\alpha$ e CX3CL1, na fisiopatologia da depressão e da ansiedade, combinadas com evidências de que altos níveis dessas citocinas são verificados em pacientes com diversos tipos de câncer, incluindo o câncer colorretal (Rich et al., 2005; Szkaradkiewicz et al., 2009; Corona et al., 2010; Grivennikov; Karin, 2011), sugerem que as citocinas podem desempenhar um papel importante na etiologia e na fenomenologia da depressão e ansiedade nessa população. 


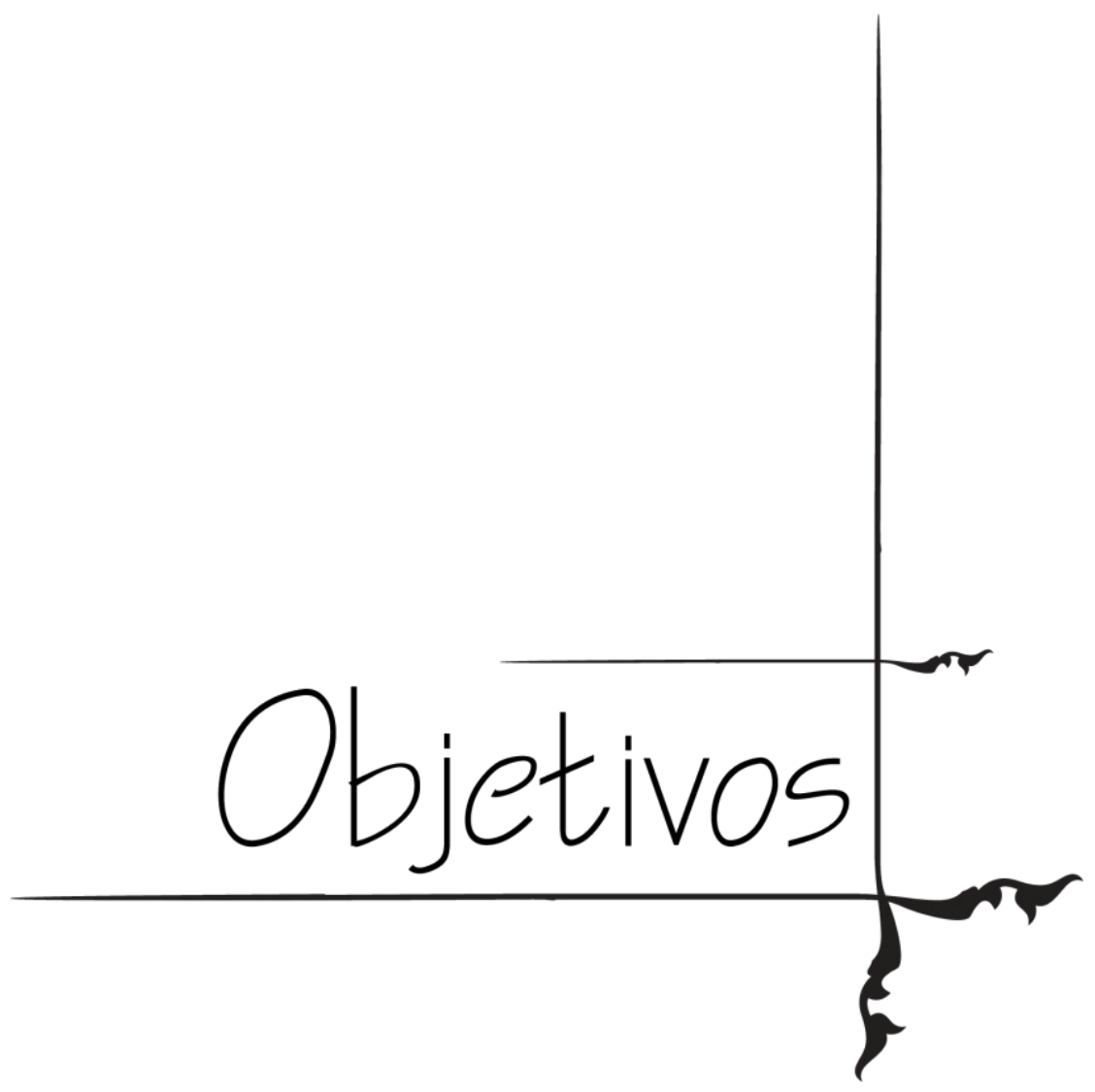




\section{OBJETIVOS}

Este estudo teve como objetivo avaliar as possíveis correlações entre os níveis séricos de citocinas, depressão e ansiedade em pacientes com câncer colorretal em diferentes estágios da terapia antitumoral. Para tanto, analisamos:

(1) o grau de alteração psíquica de portadores de adenocarcinoma colorretal em diferentes estágios da terapia antitumoral;

(2) os níveis séricos de IL-1 $\beta$, IL-6, IL-8, IL-10, IL-12, TGF- $\beta$ e TNF- $\alpha$ apresentados pelos participantes do estudo;

(3) os níveis séricos da quimiocina fractalcina (CX3CL1) apresentados pelos participantes do estudo. 


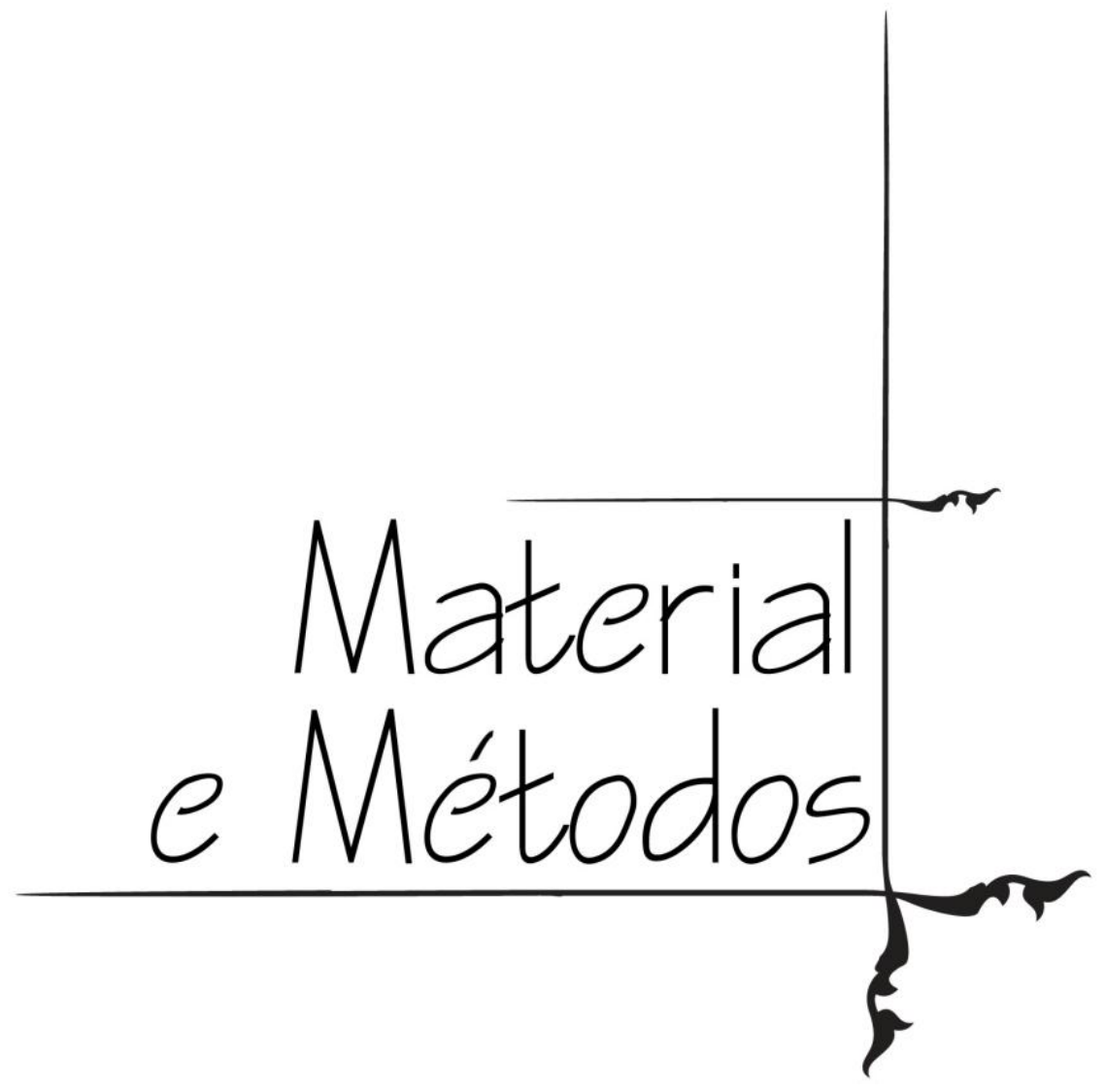




\section{MATERIAL E MÉTODOS}

O presente projeto foi aprovado pelo Comitê de Ética em Pesquisa (CEP) da EERP/USP (Processo número: 1456/2011).

\subsection{Seleção dos pacientes}

Este foi um estudo descritivo transversal, com abordagem quantitativa. Uma amostra de 100 indivíduos de ambos os sexos e maiores de 18 anos foi selecionada por conveniência de acordo com a casuística do Hospital das Clínicas da Faculdade de Medicina de Ribeirão Preto (HCFMRP/USP), divididos em cinco grupos amostrais. Grupo 1. Voluntários saudáveis livres de qualquer doença psiquiátrica ou associada com alterações do sistema imune (n=20); Grupo 2. Pacientes com diagnóstico de adenocarcinoma colorretal confirmado e que não foram submetidos à ressecção cirúrgica (n=20); Grupo 3. Pacientes submetidos à ressecção cirúrgica e que não iniciaram a terapia adjuvante $(n=20)$; Grupo 4. Pacientes em tratamento quimioterápico há cerca de 3 meses, independente do esquema de quimioterapia adjuvante aplicado (n=20); Grupo 5. Pacientes que concluíram o esquema de quimioterapia adjuvante há cerca de 6 meses (n=20).

Para todos os grupos do estudo foram utilizados como critérios de exclusão:

a) sujeitos com história prévia de doença autoimune ou inflamatória crônica, quadros infecciosos em atividade, doença hepática, renal ou diabetes mellitus;

b) pacientes diagnosticados com transtorno esquizoafetivo, transtorno bipolar, ou transtorno do pânico; 
c) indivíduos com déficit cognitivo que os impeça de compreender o delineamento do estudo e de responder ao questionário HADS, identificado através de uma observação atenta e rigorosa do pesquisador responsável pela pesquisa no momento do contato com o sujeito.

\subsection{Coleta de Dados}

Todos os dados do estudo foram coletados pelo doutorando responsável pelo projeto de pesquisa. Os dados sócio-demográficos foram constituídos de gênero, idade, escolaridade e estado civil. Os experimentos laboratoriais foram realizados no Laboratório de Genômica e Imunobiologia do Departamento de Enfermagem Materno-Infantil e Saúde Pública da EERP-USP e no Laboratório Multiusuário de Citometria da Faculdade de Medicina de Ribeirão Preto (FMRPUSP) com a supervisão de uma técnica em laboratório.

\subsection{Medidas}

Depressão e Ansiedade foram analisadas utilizando a escala HADS. O instrumento pode ser administrado por enfermeiros e foi desenvolvido para ser aplicado a pacientes de serviços nãopsiquiátricos de hospital geral ou da atenção primária. Trata-se de um instrumento curto de aferição de sofrimento psíquico que pode ser utilizado em pacientes com câncer (Zigmond \& Snaith, 1983) e já foi validado no país (Faller et al., 2003). A escala é composta por sete ítens que avaliam ansiedade e sete que avaliam a depressão. Cada item é avaliado em uma escala de quatro 
pontos, cuja pontuação máxima é de 21 para ambas as subescalas. Índices de 11 até 21 em cada subescala serão considerados um caso importante de morbidade psicológica, enquanto os escores de 8-10 representam 'borderlines' limítrofes e 0-7 representam padrões dentro da normalidade (Zigmond \& Snaith, 1983). Para a somatória de escores de ansiedade e de depressão (total de escore HADS), o limítrofe de 19 foi utilizado (baseado no trabalho de Razavi et al., 1990) para se identificar os pacientes com grave psicopatologia afetiva (Anexo 1).

\subsection{Coleta de sangue}

Paralelamente à aplicação de HADS, amostras de sangue $(8 \mathrm{~mL})$ foram coletadas de cada indivíduo após punção venosa, utilizando-se material a vácuo esterilizado e descartável (Vacutainer-Becton Dickinson, Franklin Lakes, Estados Unidos). As coletas foram realizadas pelo pesquisador responsável por este estudo, o qual é habilitado para tal procedimento. As amostras foram submetidas à centrifugação (Centrífuga Eppendorf, Hamburgo, Alemanha) a $4^{\circ} \mathrm{C}$ durante 10 minutos a $1.000 \mathrm{x}$ g para obtenção do soro que foi aliquotado em microtubos de polipropileno (Eppendorf) e armazenado a $-80^{\circ} \mathrm{C}$ até a realização dos testes imunológicos.

\subsection{Avaliação de citocinas}

As dosagens de IL-1 $\beta$, IL-6, IL-8, IL-10, IL-12, TGF- $\beta$, TNF- $\alpha$ e Fractalcina (CX3CL1) foram realizadas por meio do método Cytometric Bead Array (CBA) (BD Biosciences, San Diego, 
EUA) que se baseia no uso de esferas de poliestireno marcadas com diferentes graus de fluorescência, recobertas com anticorpos específicos, que são detectados e quantificados por citometria de fluxo.

A técnica foi realizada conforme descrito nos manuais de instrução dos kits $\mathrm{BD}^{\mathrm{TM}}$ Cytometric Bead Array (CBA): Human Inflammation (IL-1 $\beta$, IL-6, IL-8, IL-10, IL-12, TNF- $\alpha$ ), Human TGF- $\beta$ Flex Set e Human Fractalkine Flex Set, com algumas modificações. Em resumo, alíquotas de $50 \mu \mathrm{L}$ de soro dos participantes do estudo (sem diluição) foram utilizadas e $50 \mu \mathrm{L}$ dos padrões das citocinas submetidos à diluição seriada com diluente $\mathrm{G}$ do kit CBA. As amostras e os padrões foram transferidos para tubos de poliestireno de $5 \mathrm{~mL}$ e foram adicionados $12 \mathrm{~mL}$ da mistura de esferas de captura, conjugadas com anticorpos monoclonais anti-citocinas IL-1 $\beta$, IL-6, IL-8, IL-10, IL-12, TGF- $\beta$, TNF- $\alpha$ e CX3CL1. Em seguida, $20 \mu \mathrm{L}$ do coquetel de anticorpos foram conjugados com ficoeritrina e incubados por 3 horas, à temperatura ambiente. Após a incubação, as esferas de captura foram lavadas e centrifugadas a $200 \mathrm{~g}$, por 7 minutos a $18^{\circ} \mathrm{C}$, o sobrenadante foi cuidadosamente descartado, e $25 \mu \mathrm{L}$ de tampão padrão foram adicionados em cada tubo para ressuspender as partículas. Os dados foram adquiridos em citômetro de fluxo (FACSCanto II, BD, EUA) e analisados com auxílio do software específico para CBA (CBA Analyst, BD, EUA), por meio de curvas de calibração obtidas dos padrões de citocinas do kit. Após a construção das curvas, a concentração dos analitos na amostra foi determinada em pg/mL.

\subsection{Análise estatística}

Para analisar a hipótese de médias iguais entre os grupos foi utilizado o teste de KruskalWallis ANOVA seguido do pós-teste de comparação múltipla de Dunn. Os resultados foram 
expressos como média \pm desvio padrão (DP). A regressão linear simples foi utilizada para verificar a correlação entre as variáveis. O nível de significância utilizado para os testes foi de 5\%. As análise estatísticas e os gráficos foram feitos usando o programa GraphPad Prism, versão 5.0 (GraphPad Software, San Diego, CA, USA). 


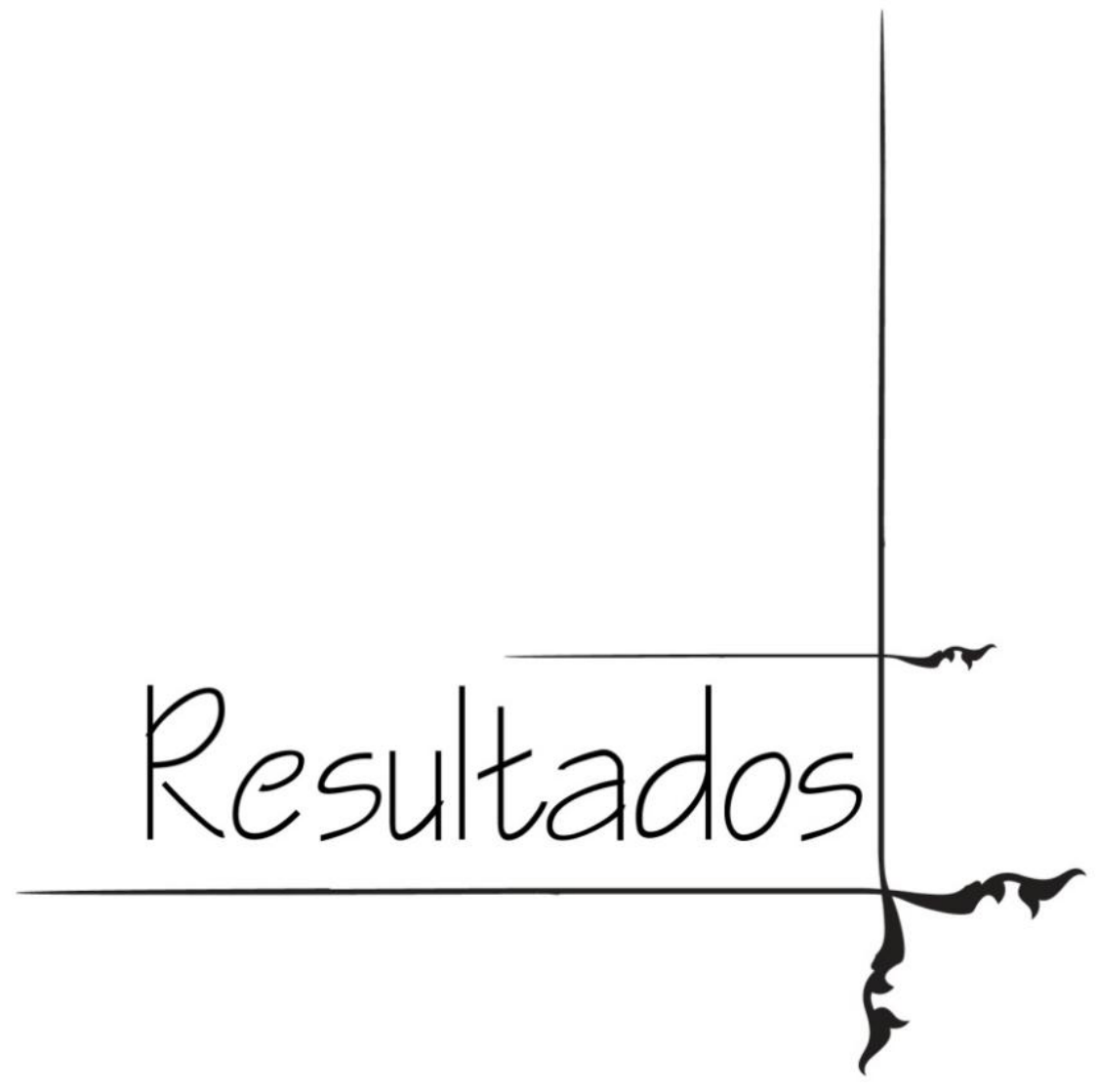




\section{RESULTADOS}

\subsection{Características clínicas e demográficas}

Em concordância com o cronograma estabelecido, foram alcançadas as quantidades de indivíduos necessárias para compor os cinco grupos do estudo. Conforme demonstrado na Tabela 1, não foram observadas diferenças significativas em relação à idade, sexo, estado civil, grau de escolaridade ou estadiamento clínico entre os grupos. Vinte voluntários saudáveis compuseram o grupo controle (G1). A idade média foi de 47,8 (DP =9) anos e 8 (40\%) eram do sexo masculino. A maioria era casada (80\%) e possuía ensino médio de escolaridade (65\%). O grupo 2, formado por pacientes com diagnóstico de CCR e que não foram submetidos à ressecção cirúrgica, apresentou média de idade de 63 (DP = 11,8) anos, sendo nove $(45 \%)$ homens. Do total do grupo, a maioria era casada (80\%), possuía nível fundamental de escolaridade (65\%) e estadio clínico III. Pacientes submetidos à ressecção cirúrgica, mas que não iniciaram a terapia adjuvante compuseram o grupo 3 , com média de idade de 56,8 ( $\mathrm{DP}=7,2)$ anos, sendo nove $(45 \%)$ homens. Entre os 20 sujeitos do grupo, nove (45\%) eram casados e possuíam nível fundamental de escolaridade; 18 (90\%) possuíam estadio clínico III. Pacientes em tratamento quimioterápico há aproximadamente 3 meses formaram o grupo 4. Este grupo apresentou média de idade de 56,4 (DP = 8,6) anos, sendo dez (50\%) homens. Doze (60\%) eram casados, dez (50\%) possuíam nível fundamental de escolaridade; 16 (80\%) possuíam estadio clínico III. O grupo 5 consistiu de pacientes que concluíram o regime de quimioterapia há cerca de 6 meses. A idade média foi de 59,9 (DP = $8,7)$ anos, dez (50\%) eram do sexo masculino e casados, nove (45\%) tinham o ensino médio 
de escolaridade; 17 (85\%) foram diagnosticados com adenocarcinoma colorretal em estadio clínico III.

Tabela 1. Características clínicas e demográficas dos participantes do estudo.

\begin{tabular}{|c|c|c|c|c|c|c|}
\hline Característica & $\begin{array}{c}\text { Grupo } 1 \\
\text { n }(\%)\end{array}$ & $\begin{array}{c}\text { Grupo } 2 \\
\text { n }(\%)\end{array}$ & $\begin{array}{c}\text { Grupo } 3 \\
\text { n }(\%)\end{array}$ & $\begin{array}{c}\text { Grupo } 4 \\
\text { n }(\%)\end{array}$ & $\begin{array}{c}\text { Grupo } 5 \\
\text { n }(\%)\end{array}$ & $\mathbf{P}$ \\
\hline $\begin{array}{l}\text { Idade } \\
(\text { média } \pm \text { DP) }\end{array}$ & $47,8 \pm 9$ & $63 \pm 11,8$ & $56,8 \pm 7,2$ & $56,4 \pm 8,6$ & $59,9 \pm 8,7$ & $\mathrm{~ns}^{*}$ \\
\hline $\begin{array}{l}\text { Sexo } \\
\quad \text { Masculino } \\
\text { Feminino }\end{array}$ & $\begin{array}{l}8(40) \\
12(60)\end{array}$ & $\begin{array}{l}9(45) \\
11(55)\end{array}$ & $\begin{array}{c}9(45) \\
11(55)\end{array}$ & $\begin{array}{l}10(50) \\
10(50)\end{array}$ & $\begin{array}{l}10(50) \\
10(50)\end{array}$ & $\mathrm{ns}^{\ddagger}$ \\
\hline $\begin{array}{l}\text { Estado Civil } \\
\text { Solteiro } \\
\text { Casado } \\
\text { Divorciado } \\
\text { Viúvo }\end{array}$ & $\begin{array}{c}2(10) \\
16(80) \\
1(5) \\
1(5)\end{array}$ & $\begin{array}{c}1(5) \\
16(80) \\
1(5) \\
2(10)\end{array}$ & $\begin{array}{l}7(35) \\
9(45) \\
- \\
4(20)\end{array}$ & $\begin{array}{c}7(35) \\
12(60) \\
- \\
1(5)\end{array}$ & $\begin{array}{c}6(30) \\
10(50) \\
- \\
4(20)\end{array}$ & $\mathrm{ns}^{\ddagger}$ \\
\hline $\begin{array}{l}\text { Escolaridade } \\
\text { Fundamental } \\
\text { Médio } \\
\text { Superior }\end{array}$ & $\begin{array}{c}6(30) \\
13(65) \\
1(5)\end{array}$ & $\begin{array}{c}13(65) \\
6(30) \\
1(5)\end{array}$ & $\begin{array}{l}9(45) \\
6(30) \\
5(25)\end{array}$ & $\begin{array}{l}10(50) \\
8(40) \\
2(10)\end{array}$ & $\begin{array}{l}8(40) \\
9(45) \\
3(15)\end{array}$ & $\mathrm{ns}^{\dagger}$ \\
\hline $\begin{array}{l}\text { Estadio Clínico } \\
\text { I } \\
\text { II } \\
\text { III } \\
\text { IV } \\
\end{array}$ & $\begin{array}{l}- \\
- \\
- \\
-\end{array}$ & $\begin{array}{c}- \\
3(15) \\
13(65) \\
4(20)\end{array}$ & $\begin{array}{c}- \\
2(10) \\
18(90) \\
- \\
\end{array}$ & $\begin{array}{c}- \\
4(20) \\
16(80) \\
-\end{array}$ & $\begin{array}{c}- \\
3(15) \\
17(85) \\
- \\
\end{array}$ & $\mathrm{ns}^{\dagger}$ \\
\hline
\end{tabular}

\subsection{Escores de ansiedade e depressão}

A tabela 2 mostra os escores de ansiedade e depressão dos participantes do estudo. Observou-se que a totalidade dos indivíduos (100\%) do grupo 1 (controle) não apresentou escores de ansiedade ou de depressão relevantes, enquanto que nos outros grupos, níveis clinicamente relevantes de ansiedade, de depressão, e uma combinação grave de ansiedade e 
depressão, indicado por um escore total de HADS superior a 19, foi verificada (G2 - grupo pré-operatório: 55\%; 50\%; 65\%, respectivamente; G3 - grupo pós-operatório: 60\%; 30\%; 60\%, respectivamente; G4 - grupo em tratamento quimioterápico: 30\%; 65\%; 60\%, respectivamente; e G5 - grupo pós-quimioterapia: 25\%, 25\%, 40\%, respectivamente).

Tabela 2. Escore de ansiedade e depressão dos participantes do estudo.

\begin{tabular}{|c|c|c|c|c|c|c|}
\hline & $\begin{array}{c}\text { Grupo 1 } \\
\text { n(\%) } \\
\end{array}$ & $\begin{array}{c}\text { Grupo } 2 \\
\text { n(\%) } \\
\end{array}$ & $\begin{array}{c}\text { Grupo } 3 \\
\text { n (\%) } \\
\end{array}$ & $\begin{array}{c}\text { Grupo } 4 \\
\text { n }(\%) \\
\end{array}$ & $\begin{array}{c}\text { Grupo } 5 \\
\text { n(\%) } \\
\end{array}$ & $\mathbf{P}$ \\
\hline \multicolumn{7}{|l|}{ Ansiedade } \\
\hline $0-7$ & $17(85)$ & $3(15)$ & $4(20)$ & $5(25)$ & $6(30)$ & \multirow{4}{*}{$<0.001^{\ddagger}$} \\
\hline $8-10$ & $3(15)$ & $6(30)$ & $4(20)$ & $9(45)$ & $9(45)$ & \\
\hline $11-21$ & $0(0)$ & $11(55)$ & $12(60)$ & $6(30)$ & $5(25)$ & \\
\hline Média \pm DP & $3,2 \pm 2,7$ & $11 \pm 3,7$ & $11 \pm 3,7$ & $10 \pm 3$ & $9,2 \pm 3,3$ & \\
\hline \multicolumn{7}{|l|}{ Depressão } \\
\hline $0-7$ & $20(100)$ & $3(15)$ & $5(25)$ & $3(15)$ & $3(15)$ & \multirow{4}{*}{$<0.001$} \\
\hline $8-10$ & $0(0)$ & $7(35)$ & $9(45)$ & $4(20)$ & $12(60)$ & \\
\hline $11-21$ & $0(0)$ & $10(50)$ & $6(30)$ & $13(65)$ & $5(25)$ & \\
\hline Média \pm DP & $2,5 \pm 2,3$ & $11 \pm 3,4$ & $9,9 \pm 3,7$ & $12 \pm 3,2$ & $9,3 \pm 2,9$ & \\
\hline \multicolumn{7}{|c|}{ Ansiedade e Depressão (total de escore HADS) } \\
\hline$\leq 19$ & $20(100)$ & $7(35)$ & $8(40)$ & $8(40)$ & $12(60)$ & \multirow{2}{*}{$<0.001$} \\
\hline$>19$ & $0(0)$ & $13(65)$ & $12(60)$ & $12(60)$ & $8(40)$ & \\
\hline
\end{tabular}

\subsection{Níveis séricos de citocinas}

Um padrão de produção semelhante foi observado para as citocinas pró-inflamatórias avaliadas. IL-1, IL-6, IL-8, TNF- $\alpha$ e Fractalcina foram encontradas em níveis elevados nos pacientes com CCR em estágio pré (G2) e pós-operatório (G3). Estes níveis foram, contudo, reduzidos durante (G4) e após (G5) o tratamento quimioterápico (Figura 1). Além disso, 
verificamos níveis diminuídos de IL-10 no soro dos pacientes dos grupos 2 e 3 (pré e pósoperatório).
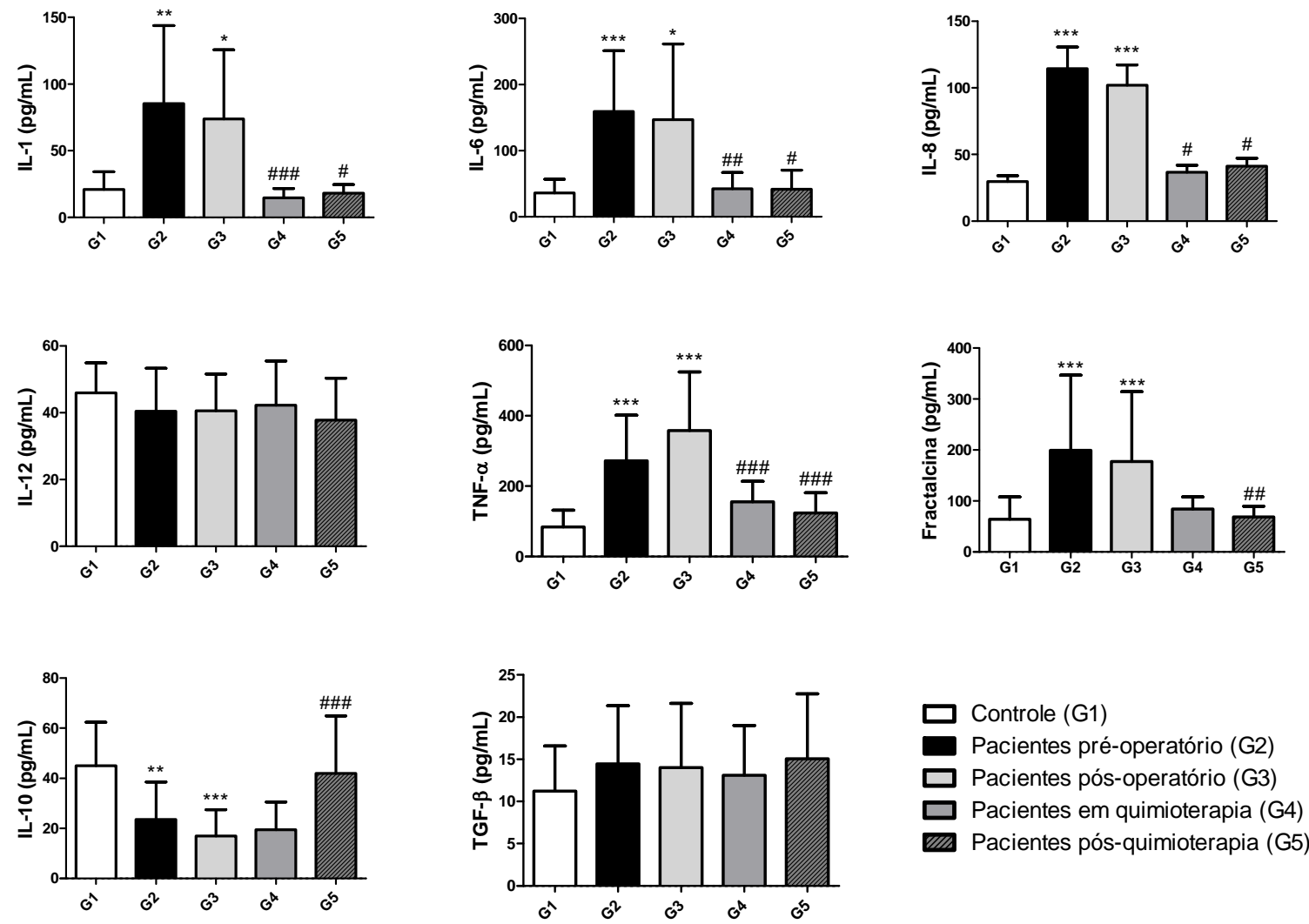

Figura 1. Concentrações plasmáticas das citocinas IL-1beta, IL-6, IL-8, TNF-alfa, IL-10, IL-12, TGFbeta e Fractalcina. Os dados representam a média \pm DP de análises CBA de amostras de sangue de G1) voluntários saudáveis (controle); G2) Pacientes no estágio pré-operatório, não submetidos à resecção cirúrgica do tumor colorretal; G3) Pacientes no estágio pós-operatório que ainda não iniciaram o tratamento quimioterápico adjuvante; G4) Pacientes em tratamento quimioterápico há 3 meses; G5) Pacientes que concluíram a quimioterapia há pelo menos 6 meses. $\mathrm{n}=20$ para cada grupo. $* \mathrm{p}<0.05$ vs Voluntários saudáveis (G1), \#P<0.05 vs Pós-operatório (G3). 


\subsection{Correlações entre escores HADS e níveis de citocinas}

As associações entre os escores HADS e os níveis de cada citocina são descritas na Tabela 3. No grupo controle (G1), não foram encontradas correlações entre escores HADS e os níveis séricos das citocinas analisadas. Nos demais grupos de pacientes com CCR (antes da cirurgia, antes da quimioterapia, no meio da quimioterapia e 6 meses após o término da quimioterapia; G2, G3, G4 e G5, respectivamente), a pontuação HADS para os níveis de ansiedade, depressão, e ansiedade e depressão juntos, associou-se positivamente com as concentrações de IL-1 (G2: r=0.48; r=0.49; r=0.59, respectivamente; G3: r=0.48; r=0.49; $\mathrm{r}=0.59$, respectivamente; G4: $\mathrm{r}=0.48 ; \mathrm{r}=0.49 ; \mathrm{r}=0.59$, respectivamente; G5: $\mathrm{r}=0.38 ; \mathrm{r}=0.28$; $\mathrm{r}=0.40$, respectivamente), IL-6 (G2: r=0.48; r=0.36; r=0.49, respectivamente; G3: $\mathrm{r}=0.48$; $\mathrm{r}=0.49 ; \mathrm{r}=0.59$, respectivamente; G4: $\mathrm{r}=0.48 ; \mathrm{r}=0.49 ; \mathrm{r}=0.59$, respectivamente, G5: $\mathrm{r}=0.27$; $\mathrm{r}=0.19 ; \mathrm{r}=0.22$, respectivamente), IL-8 (G2: r=0.62; r=0.44; r=0.65, respectivamente; G3: $\mathrm{r}=0.48 ; \mathrm{r}=0.49 ; \mathrm{r}=0.59$, respectivamente; $\mathbf{G 4}: \mathrm{r}=0.48 ; \mathrm{r}=0.49 ; \mathrm{r}=0.59$, respectivamente; G5: $\mathrm{r}=0.48 ; \quad \mathrm{r}=0.28 ; \quad \mathrm{r}=0.46, \quad$ respectivamente $), \quad \mathrm{TNF}-\alpha \quad(\mathbf{G} 2: \quad \mathrm{r}=0.29 ; \quad \mathrm{r}=0.28 ; \quad \mathrm{r}=0.35$, respectivamente; G3: r=0.48; r=0.49; r=0.59, respectivamente; G4: r=0.48; r=0.49; r=0.59, respectivamente; G5: $\mathrm{r}=0.15 ; \mathrm{r}=0.14 ; \mathrm{r}=0.22$, respectivamente) e Fractalcina $(\mathbf{G 2}: \mathrm{r}=0.45$; $\mathrm{r}=0.35 ; \mathrm{r}=0.26$, respectivamente; G3: $\mathrm{r}=0.32 ; \mathrm{r}=0.40 ; \mathrm{r}=0.42$, respectivamente; G4: $\mathrm{r}=0.40$; $\mathrm{r}=0.24 ; \mathrm{r}=0.38$, respectivamente; G5: $\mathrm{r}=0.25 ; \mathrm{r}=0.16 ; \mathrm{r}=0.26$, respectivamente). Observamos correlação negativa entre escores HADS, tanto para ansiedade quanto para depressão e ansiedade e depressão associados, e níveis séricos de IL-10 (G2: r=-0.36; r=-0.25; r=-0.21, respectivamente; G3: $\mathrm{r}=-0.28 ; \mathrm{r}=-0.25 ; \mathrm{r}=-0.24$, respectivamente, G5: $\mathrm{r}=-0.29 ; \mathrm{r}=-0.12 ; \mathrm{r}=-$ 0.25, respectivamente). Não houve associação entre a pontuação HADS e os níveis de IL-12 e TGF- $\beta$. 
Tabela 3. Correlações entre níveis séricos de citocinas e escores HADS.

\begin{tabular}{|c|c|c|c|c|c|c|c|c|}
\hline & IL-1 & IL-6 & IL-8 & IL-10 & IL-12 & TNF- $\alpha$ & TGF- $\beta$ & Fractalcina \\
\hline \multicolumn{9}{|l|}{ Grupo 1} \\
\hline Ansiedade & 0.19 & 0.12 & 0.18 & -0.14 & 0.11 & 0.15 & -0.11 & 0.16 \\
\hline Depressão & 0.12 & 0.13 & 0.12 & -0.17 & 0.17 & 0.08 & -0.12 & 0.18 \\
\hline$A$ e D & 0.12 & 0.14 & 0.22 & -0.16 & 0.14 & 0.09 & -0.12 & 0.16 \\
\hline \multicolumn{9}{|l|}{ Grupo 2} \\
\hline Ansiedade & $0.48 * * *$ & $0.49 * * *$ & $0.62 * * *$ & $-0.36 * *$ & -0.14 & $0.29 *$ & -0.19 & $0.45 * *$ \\
\hline Depressão & $0.49 * *$ & $0.36 * *$ & $0.44 * *$ & $-0.25^{*}$ & -0.02 & $0.28 *$ & -0.15 & $0.35 * *$ \\
\hline$A$ e D & $0.59 * * *$ & $0.49 * * *$ & $0.65 * * *$ & $-0.21^{*}$ & -0.05 & $0.35 * *$ & -0.11 & $0.26^{*}$ \\
\hline \multicolumn{9}{|l|}{ Grupo 3} \\
\hline Ansiedade & $0.32 * *$ & $0.47 * * *$ & $0.21 *$ & $-0.28^{*}$ & -0.20 & $0.36 * *$ & 0.10 & $0.32 * *$ \\
\hline Depressão & $0.22 *$ & $0.28 *$ & $0.23 *$ & $-0.25^{*}$ & -0.10 & $0.24 *$ & 0.05 & $0.40 * *$ \\
\hline$A$ e D & $0.24 *$ & $0,79 * * *$ & $0.27 *$ & $-0.24^{*}$ & -0.16 & $0.25^{*}$ & 0.05 & $0.42 * *$ \\
\hline \multicolumn{9}{|l|}{ Grupo 4} \\
\hline Ansiedade & $0.60 * * *$ & $0.55 * * *$ & $0.20 *$ & -0.15 & -0.15 & $0.30 *$ & -0.15 & $0.40 * *$ \\
\hline Depressão & $0.26^{*}$ & $0.51 * *$ & $0.50 * *$ & -0.14 & -0.13 & $0.38 * *$ & -0.13 & $0.24 *$ \\
\hline A e D & $0.28 *$ & $0.45^{* *}$ & $0.50 * *$ & -0.14 & -0.12 & $0.49 * *$ & -0.09 & $0.38 * *$ \\
\hline \multicolumn{9}{|l|}{ Grupo 5} \\
\hline Ansiedade & $0.38 * *$ & $0.27 *$ & $0.48 * * *$ & $-0.29^{*}$ & -0.12 & 0.15 & -0.13 & $0.25 *$ \\
\hline Depressão & $0.28 *$ & 0.19 & $0.28 *$ & -0.12 & $-0.21 *$ & 0.14 & -0.14 & 0.16 \\
\hline$A$ e D & $0.40^{*}$ & $0.22 * *$ & $0.46 * *$ & $-0.25^{*}$ & -0.13 & $0.22 *$ & -0.19 & $0.26 *$ \\
\hline
\end{tabular}

A e D = Ansiedade e Depressão somadas (total de escore HADS)

$* \mathrm{p}<0.05 ; * * \mathrm{p}<0.001 ; * * * \mathrm{p}<0.0001$ (Regressão Linear Simples) 


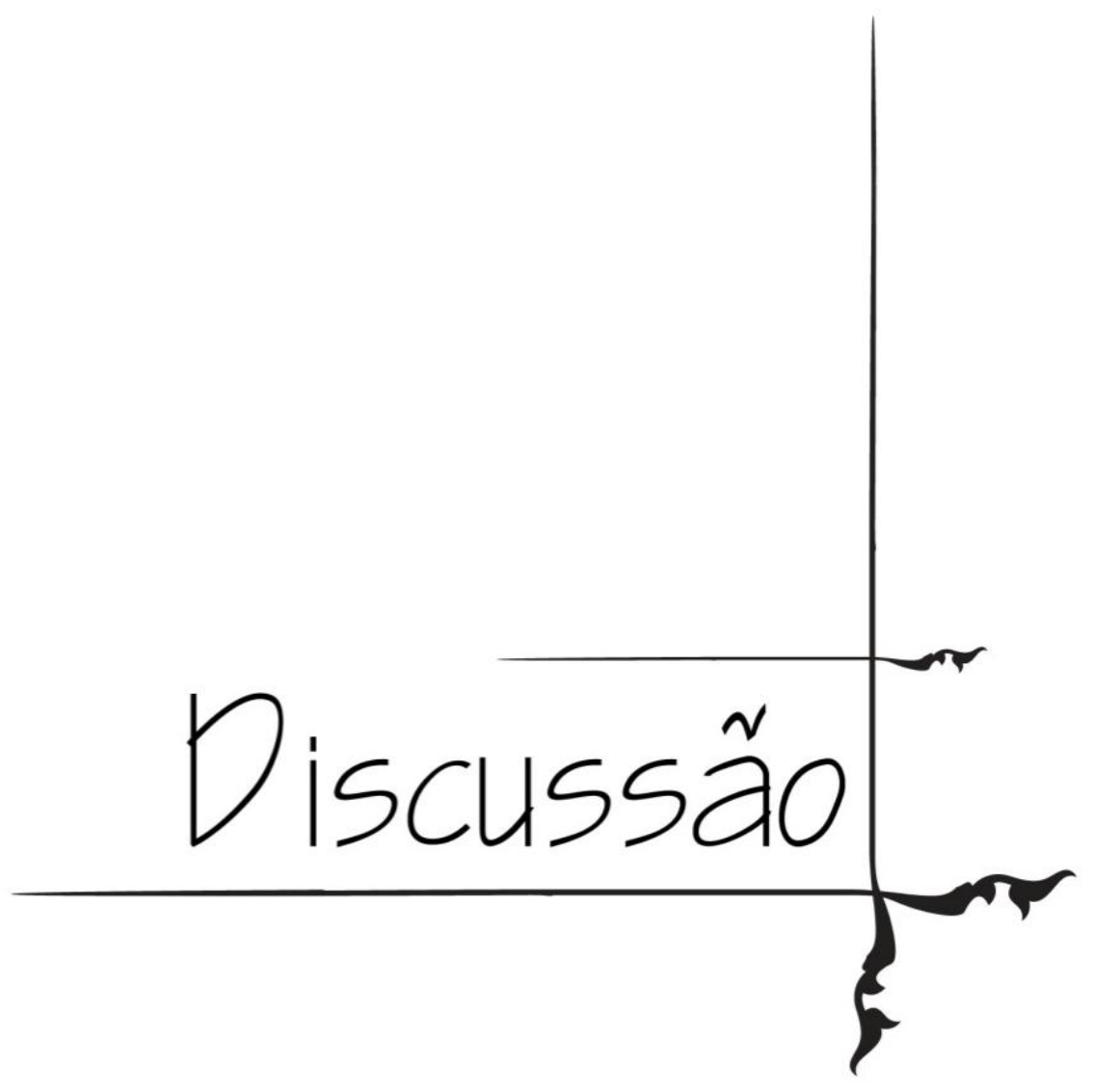




\section{DISCUSSÃO}

Os altos níveis de citocinas pró-inflamatórias em pacientes com diferentes tipos de câncer, incluindo o CCR (Rich et al., 2005; Szkaradkiewicz et al., 2009; Grivennikov; Karin, 2011), e também em pacientes com depressão (Madden, 2003; Vismari et al., 2008), combinados com a alta prevalência de depressão em pacientes com câncer sugerem que as citocinas podem ter um papel importante na etiologia e patofisiologia da depressão e ansiedade nestes indivíduos. Corroborando a hipótese do trabalho, verificamos que a ansiedade e/ou depressão correlacionaram-se positivamente com os níveis séricos de IL-1, IL6, IL-8, TNF- $\alpha$ e fractalcina em pacientes com CCR em diferentes fases da terapia antitumoral. Encontramos também uma correlação negativa entre esses distúrbios psicológicos e as concentrações séricas de IL-10.

A "hipótese de citocinas", baseada em achados recentes de vários campos de estudo como endocrinologia, imunologia e neurociência, sugere que as alterações no comportamento observadas em pacientes com câncer sejam causadas por citocinas pró-inflamatórias produzidas diretamente por tumores ou por outras células do microambiente tumoral (Rich et al., 2005). Estas citocinas, ao atuarem no sistema nervoso central por meio de sua ligação a receptores específicos presentes nas células nervosas, podem afetar o metabolismo da serotonina em virtude da redução dos níveis de triptofano, além de exercerem um potente efeito direto sobre o eixo HHA, levando a um aumento da resposta inflamatória por interromperem o funcionamento de receptores de glicocorticóides (Janssen et al., 2010). As citocinas podem também modificar a plasticidade neural, como evidenciado por achados estruturais e de imagem funcional de alterações em importantes redes neurais associadas aos transtornos de humor tais como o hipocampo e outras regiões límbicas, bem como as regiões 
corticais (Miller et al., 2009). Além disso, é sabido que níveis elevados de IL-1 $\beta$ e TNF- $\alpha$ levam a uma regulação positiva da expressão do transportador de serotonina em humanos, aumentando a recaptação desta monoamina e diminuindo a neurotransmissão serotonérgica (Morikawa et al., 1998 e Mossner et al., 1998). Em conjunto, estes dados da literatura, associados aos elevados níveis séricos de IL-1, IL-6, IL-8 e TNF- $\alpha$ encontrados nos pacientes com CCR deste estudo, apontam para a existência de uma origem biológica para a depressão nestes pacientes, indicando que depressão e ansiedade podem não ser apenas uma reação ao diagnóstico de câncer. Esta hipótese é suportada ainda por estudos que mostram uma correlação entre os níveis séricos de IL-6 e sintomas de depressão ou alteração do funcionamento psicossocial em pacientes com tumores de pâncreas e ovário (Spath-Schwalbe et al., 1998; Musselman et al., 2001).

Em geral, postula-se que citocinas pró-inflamatórias influenciem fortemente o estado imunológico de pacientes portadores de diversos tipos de tumores. Entre as citocinas, IL-1, IL-6, IL-8, TNF- $\alpha$ e a quimiocina Fractalcina possuem um papel central no desenvolvimento de processos inflamatórios crônicos como tumores (Baier et al., 2005; Biasi et al., 2012). Em concordância com os resultados demonstrados anteriormente por outros autores (Kamińska et al, 2000; Grivennikov; Karin, 2011; Ning; Lenz, 2012; Krzystek-Korpacka et al., 2013), verificamos níveis elevados das citocinas pró-inflamatórias IL-1, IL-6, IL-8, TNF- $\alpha$ em pacientes com CCR que não haviam iniciado o tratamento quimioterápico, independentemente de terem se submetido ou não à ressecção cirúrgica. Estes pacientes também apresentaram níveis aumentados de fractalcina. Estes foram os grupos nos quais observamos os maiores escores de depressão e ansiedade, observação que também corrobora estudos anteriores (Tsunoda et al., 2005; Wedding et al; 2008). Por outro lado, os níveis séricos destas citocinas e de fractalcina foram reduzidos durante e/ou após a quimioterapia. A mielossupressão comumente induzida pelos quimioterápicos antitumorais pode ser apontada 
como uma das principais causas da redução de citocinas sistêmicas observada nos pacientes que se encontravam em tratamento (G4) (Zhao et al., 2010; Pander et al., 2011). No grupo de pacientes que já finalizaram a quimioterapia (G5), a redução observada está em consonância com as constatações prévias de que os sintomas psicológicos tendem a diminuir com o passar do tempo, de forma que a maioria dos pacientes portadores de câncer tem seu padrão de humor normalizado com o término do tratamento (Andersen et al., 1989).

Atualmente, as associações entre inflamação e câncer estão bem estabelecidas e aceitase que a inflamação crônica seja importante na geração de malignidade através da liberação de citocinas pró-inflamatórias e ativação contínua das vias de sinalização, como NF-kB e STAT3 (Landskron et al., 2014). Além disso, estas citocinas estão também envolvidas no crescimento tumoral, por estimular a proliferação de células tumorais e a evasão da imunovigilância (Jess et al., 2006; Atreya et al, 2008). Sabe-se que além da inflamação crônica aumentar o risco para o desenvolvimento de câncer, os próprios tumores induzem respostas inflamatórias (Hanahan; Weinberg, 2011; Landskron et al., 2014). A regulação do processo inflamatório envolve um equilíbrio entre as citocinas pró e anti-inflamatórias (Moura et al., 2001). IL-10 e TGF- $\beta$ são as citocinas anti-inflamatórias melhor estudadas e desempenham um papel importante na regulação da resposta de células $\mathrm{T}$, inibindo a produção de citocinas pró-inflamatórias. Um desequilíbrio na produção de IL-10 ou TGF- $\beta$ pode induzir uma profunda imunossupressão e favorecer o desenvolvimento de carcinoma colorretal, além de predizer um prognóstico ruim para pacientes portadores deste tipo de câncer (Haupt et al., 1997; Cui et al., 2007; Xu; Pasche, 2007). Níveis diminuídos de IL-10 (Szkaradkiewicz et al., 2009) e TGF- $\beta$ (Xu; Pasche, 2007) são comumente observados em pacientes com CCR. Corroborando com esses dados, verificamos níveis diminuidos de IL-10 no soro de pacientes com CCR em estágio pré e pós-operatório. Os níveis de TGF- $\beta$, no 
entanto, foram semelhantes em todos os grupos, não apresentando correlação com as comorbidades psicológicas estudadas.

No que concerne à fractalcina, também correlacionada à manifestação de depressão e ansiedade pelos pacientes com câncer deste estudo, sabe-se que, além de atuar no recrutamento de linfócitos para o tecido tumoral, a mesma regula a ativação da microglia no sistema nervoso central ao interagir com o seu receptor (Hurst et al., 2009). A expressão de seus receptores é heterogênea na população humana (Hatori et al., 2002) e, de acordo com estudos em animais (Corona et al., 2010), a baixa expressão do receptor CX3CR1 tornaria estes indivíduos mais susceptíveis a desordens comportamentais, incluindo a depressão. A fractalcina também participa de vários mecanismos não-imunes que podem ser relevantes para transtornos psiquiátricos, incluindo: inibição da neurotransmissão serotoninérgica pelo aumento da atividade do ácido gama-aminobutírico (GABA) em neurônios serotonérgicos, inibição da atividade glutamatérgica em neurônios do hipocampo, e processos de regulação da neuroplasticidade, como potenciação de longo prazo (Ragozzino et al., 2006; Heinisch; Kirby, 2009; Rogers et al., 2011; Briones et al., 2014).

Em resumo, os nossos resultados mostram que os pacientes com CCR em diferentes estágios da terapia antitumoral apresentam significativos níveis de ansiedade e/ou depressão e estes níveis oscilam ao longo do tratamento, correlacionando-se com as concentrações séricas de citocinas pró-inflamatórias e da quimiocina fractalcina. De forma interessante, observamos que os pacientes do grupo 3 (grupo pós-operatório cujos pacientes não começaram a quimioterapia) experimentam mais estresse em todas as análises, possivelmente devido à expectativa do início do tratamento quimioterápico e a preocupação com a possibilidade de efeitos colaterais. Por sua vez, os pacientes do grupo 4 (pacientes em quimioterapia) mostraram altas taxas de depressão, o que pode estar relacionado com os efeitos secundários do tratamento, tais como a perda de peso, perda de cabelo, caquexia, náuseas, e outros. Estes 
efeitos podem ser especialmente importantes na população idosa de pacientes com CCR (Klemm et al., 2000).

Embora os resultados indiquem que os níveis de ansiedade e depressão diminuíram ao longo do tempo, um número significativo de pacientes apresentou elevados níveis de ansiedade e depressão 6 meses após finalizada a quimioterapia. Isto sugere que todos os pacientes com CCR devem ser examinados rotineiramente em relação a comorbidades psicológicas. Além disso, uma vez que os pacientes com CCR apresentaram níveis elevados de citocinas pró-inflamatórias e da quimiocina fractalcina, assume-se que os mesmos possuem particular risco de apresentarem alterações psicológicas. Assim, a inflamação comumente observada no microambiente tumoral e sistemicamente proporciona uma oportunidade única no estudo do papel da inflamação na fisiopatologia da depressão e dos mecanismos biológicos pelos quais a depressão pode influenciar a incidência de câncer, a progressão tumoral a morbidade e a mortalidade destes pacientes. Neste cenário, a dosagem sérica de citocinas e da fractalcina, realizada de forma rotineira, pode ser usada como um marcador para o risco de manifestação de depressão e ansiedade em pacientes com câncer no momento do diagnóstico e durante o tratamento quimioterápico (Vodermaier et al., 2011).

Os resultados de nossa investigação possuem importantes implicações clínicas. Em primeiro lugar, destacamos a necessidade de triagem para alterações emocionais, a fim de detectar pacientes que possam vir a apresentar uma adaptação ruim à doença e aos tratamentos. Além disso, é preciso estar ciente do ajustamento emocional dos pacientes nas diferentes fases da experiência do câncer e monitorar os níveis de ansiedade e depressão ao longo da trajetória da doença, incluindo o período após o término dos tratamentos. Outro fator necessário é a intervenção psicossocial para pacientes com câncer a fim de melhorar o ajustamento psicossocial e a qualidade de vida. Essas intervenções devem considerar o estágio da doença que o indivíduo está e serem adaptadas para as questões específicas dessa fase. 


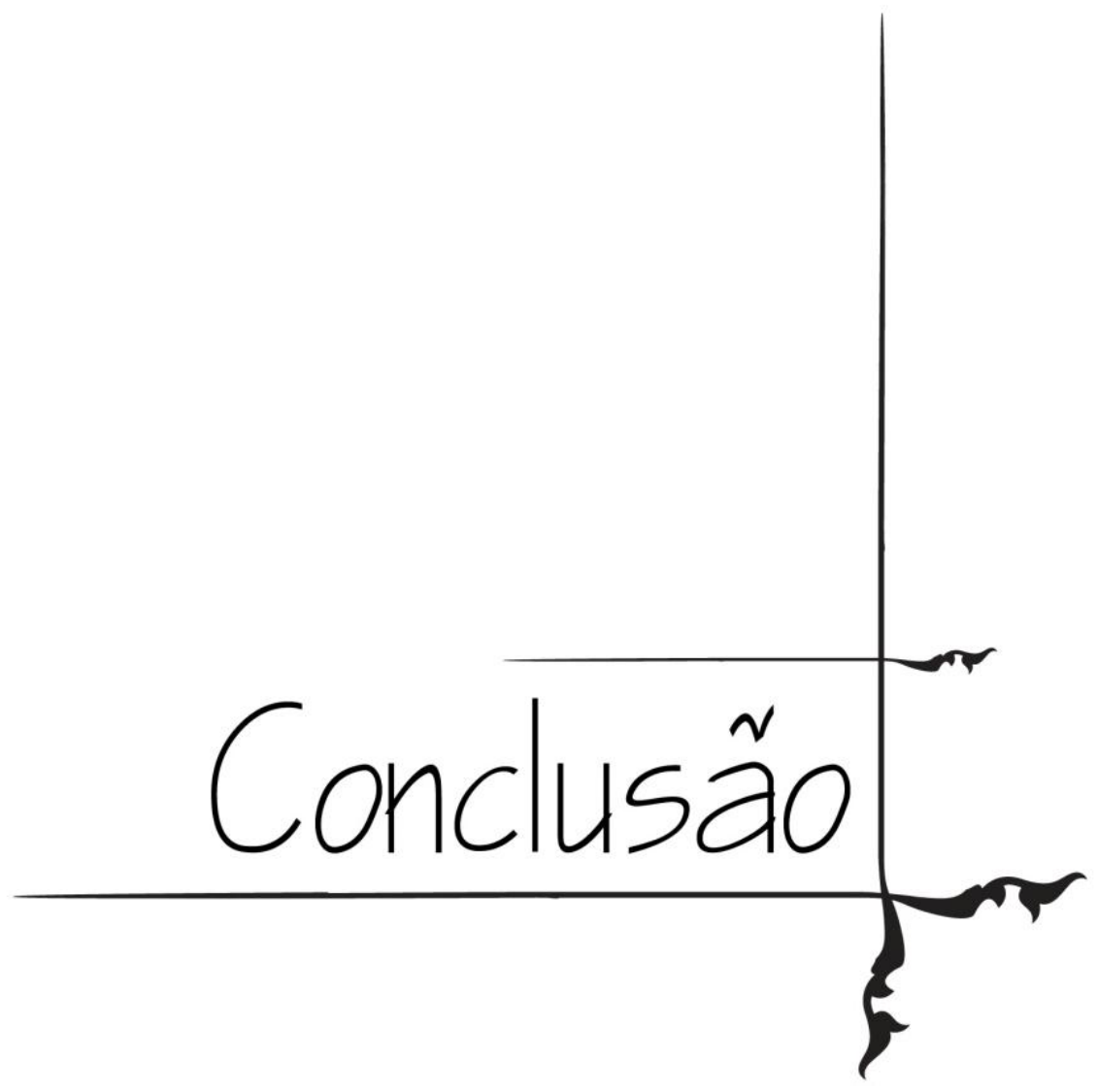




\section{CONCLUSÃO}

Nossos resultados demonstram que os níveis séricos das citocinas pró-inflamatórias IL-1, IL-6, IL-8, TNF- $\alpha$ e da quimiocina CX3CL1 correlacionam-se com a manifestação de ansiedade e depressão em pacientes com CCR em diferentes estágios da terapia antitumoral, sugerindo que estas moléculas estão envolvidas na fisiopatologia dessas comorbidades psicológicas. 


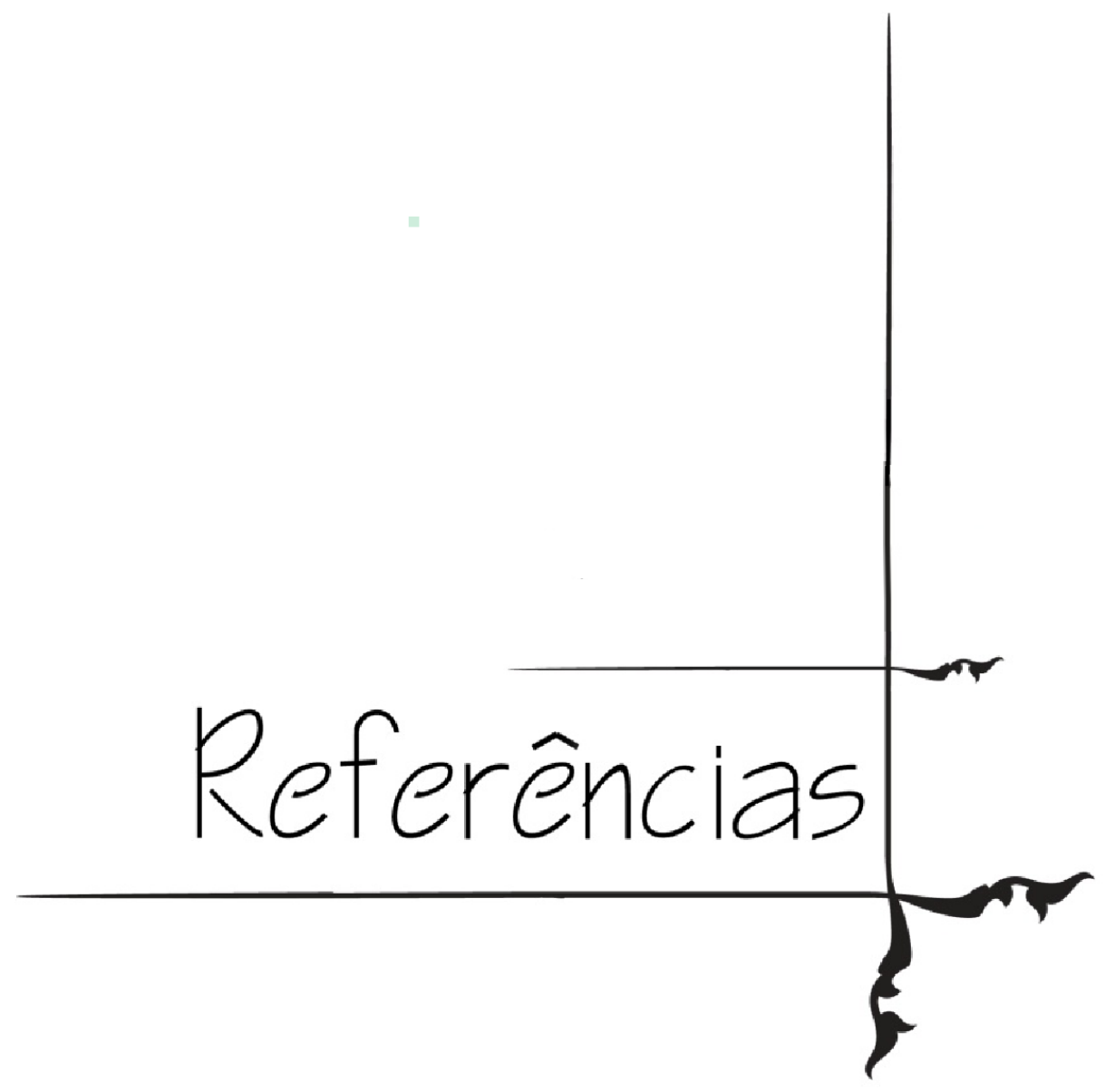


REFERÊNCIAS

Agalliu, I.; Xue, X.; Cushman, M.; Cornell, E.; Hsing, A. W.; Kaplan, R. C.; Anastos, K.; Rajpathak, S.; Ho, G. Y. Detectability and reproducibility of plasma levels of chemokines and soluble receptors. Results Immunol, 3: 79-84, 2013.

Alacacioglu, O.; Omer, B.; Ozkan, G.; Ilhan, O.; Meliha, D.; Ugur, Y. Quality of life, anxiety, and depression in Turkish colorectal cancer patients. Support Care Cancer, 18: 417-421, 2010.

Andersen, B.; Andersen, B.; deProsse, C. Controlled prospective longitudinal study of women with breast cancer. II. Psychological outcomes. Journal of Consulting and Clinical Psychology, 57: 692-697. 1989.

Atreya, I.; Atreya, R.; Neurath, M. F. NF-kappaB in inflammatory bowel disease. J Intern Med, 263: 591-596, 2008.

Baier, P.K.; Wolff-Vorbeck, G.; Eggstein, S.; Baumgartner, U.; Hopt, U.T. Cytokine Expression in Colon Carcinoma. Anticancer Research, 25: 2135-40, 2005.

Ballenger C. J.; Davidson, J. R.; Lecrubier, Y.; Nutt, D. J.; Jones, R. D.; Berard, R. M.; et al. Consensus statement on depression, anxiety, and oncology. J Clin Psychiatry, 62 (Suppl 8): 64-7, 2001.

Biasi, F.; Guina, T.; Maina, M.; Nano, M.; Falcone, A.; Aroasio, E.; Saracco, G. M.; Papotti, M.; Leonarduzzi, G.; Poli, G. Progressive increase of matrix metalloprotease-9 and 
interleukin-8 serum levels during carcinogenic process in human colorectal tract. PLoS ONE, 7(7): e41839, 2012.

Botega, N. J.; Pondé, M. P.; Medeiros, P.; Lima, M. G.; Guerreiro, C. A. M. Validação da escala hospitalar de ansiedade e depressão (HAD) em pacientes epiléticos ambulatoriais. $J$ Bras Psiquiatr, 47 (6): 258-89, 1998.

Bottino, S. M. B.; Fráguas, R.; Gattaz, W. F. Depression and cancer. Rev Psiq Clín., 36 (3): 109-15, 2009.

Brasil. Ministério da Saúde. Intituto Nacional do Câncer. Estimativas/2014 - Incidência do câncer no Brasil. Rio de Janeiro: INCA, 2013, Disponível em: http://www.inca.gov.br. Acesso em: 05/12/2013.

Briones, T. L.; Woods, J.; Wadowska, M. Chronic neuroinflammation and cognitive impairment following transient global cerebral ischemia: role of fractalkine/CX3CR1 signaling. Journal of Neuroinflammation, 11: 13, 2014.

Calil, H. M.; Guerra, A. B. G. Depressão: uma doença mental? Ciência Hoje, 34 (301): 28-37, 2004.

Capuron, L.; Dantzer, R. Cytokines and depression: the need for a new paradigm. Brain Behav Immun., 17 (Suppl 1): 119-124, 2003.

Carmack, C. L.; Basen-Engquist, K.; Yuan, Y.; Greisinger, A.; Rodriguez-Bigas, M.; Wolff, R.A.; Barker, T.; Baum, G.; Pennebaker, J. W. Feasibility of an Expressive-Disclosure 
Group Intervention for Post-Treatment Colorectal Cancer Patients. Cancer Month, 00, 2011.

Castillo, A. R. G. L.; Recondo, R.; Asbahr, F. R.; Manfro, G. G. Transtornos de ansiedade. Rev Bras Psiquiatr., 22 (Supl II): 20-3, 2000.

Castrén, E.; Voikar, V.; Rantamaki, T. Role of neurotrophic factors in depression. Curr Opin Pharmacol., 7 (1): 18-21, 2007.

Charney, D. S.; Drevets, W. C. Neurobiological basis of anxiety disorders. In: Davis, K.L. et al. Neuropsychopharmacology: the fifth generation of progress. Baltimore: Lippincott Williams \& Wilkins, 901-930, 2004.

Checkley S. The neuroendocrinology of depression and chronic stress. Br Med Bull, 52 (3): 597-617, 1996.

Ciaramella, A.; Poli, P. Assessment of depression among cancer patients: the role of pain, cancer type and treatment. Psychooncology, 10 (2): 156-65, 2001.

Corona, A. W.; Huang, Y.; O'Connor, J. C.; Dantzer, R.; Kelley, K. W.; Popovich, P. G.; Godbout, J. P. Fractalkine receptor (CX3CR1) deficiency sensitizes mice to the behavioral changes induced by lipopolysaccharide. J Neuroinflammation., 7: 93, 2010.

Cui, G.; Goll, R.; Olsen, T.; Steigen, S.E.; Husebekk, A.; Vonen, B.; Florholmen, J. Reduced expression of microenvironmental Th1 cytokines accompanies adenomas-carcinomas sequence of colorectum. Cancer Immunol Immunother; 56: 985-95, 2007. 
Dhabhar, F. S.; Burke, H. M.; Epel, E. S.; Mellon, S. H.; Rosser, R.; Reus, V. I.; Wolkowitz, O. M. Low serum IL-10 concentrations and loss of regulatory association between IL-6 and IL-10 in adults with major depression. Journal of Psychiatric Research, 43: 962-969, 2009.

Dunn, J.; Lynch, B.; Aitken, J.; Leggett, B.; Pakenham, K.; Newman, B. Quality of life and colorectal cancer: a review. Aust N Z J Public Health, 27: 41-53, 2003.

Dunn. J.; Lynch, B.; Rinaldis, M.; Pakenham, K.; Mcpherson, L.; Owen, N.; Leggett, B.; Newman,B.; Aitken, J. Dimensions of quality of life and psychosocial variables most salient to colorectal cancer patients. Psycho-Oncology, 15: 20-30, 2006.

Edge, S. B.; Byrd, D. R.; Compton, C. C. et al. AJCC Cancer Staging Manual. 7th ed. Springer; 2010.

Faller, H.; Olshausen, B.; Flentje, M. Emotional distress and need for support in breast cancer patients undergoing radiotherapy. Psychotherapie und Medizinische Psychologie, 53, 229$235,2003$.

Ferlay, J.; Soerjomataram, I.; Ervik, M. et al. GLOBOCAN 2012 v1.0, Cancer incidence and mortality worldwide in 2012: IARC Cancer Base No. 11 [Internet]. Lyon, France: International Agency for Research on Cancer, 2013. Disponível em: http://globocan.iarc.fr. Acesso em 18/01/2014.

González, B. G.; Escobar, A. Neuroanatomía del estrés. Rev. Mex. Neuroc, 3 (5): 273-282, 2002. 
Gray, J. A.; McNaughton, N. The neuropsychology of anxiety: an enquiry into the functions of the septo-hippocampal system. 2th ed. Oxford: Oxford University Press, 2000.

Greenberg, D. B. Barriers to the treatment of depression in cancer patients. J Natl Cancer Inst Monogr, 32: 127-35, 2004.

Grivennikov S. I.; Karin, M. Inflammatory cytokines in cancer: tumour necrosis factor and interleukin 6 take the stage. Ann Rheum Dis., 70 (Suppl 1): 104-108, 2011.

Gunderson, L. L., Jessup, J. M., Sargent, D. J. et al. Revised TN categorization for colon cancer based on national survival outcomes data. J Clin Oncol, 28:264-71, 2010.

Hanahan, D.; Weinberg, R. A. Hallmarks of cancer: the next generation. Cell, 144 (5): 646674, 2011.

Hatori, K.; Nagai, A.; Heisel, R.; Ryu, J.K.; Kim, S.U. Fractalkine and fractalkine receptors in human neurons and glial cells. J Neurosci Res., 69 (3): 418-26, 2002.

Haupt, W.; Hohenberger, W.; Mueller, R.; et al. Association between reoperative acute phase response and postoperative complications. Eur J Surg, 163: 39-44, 1997.

Heinisch, S.; Kirby, L. G. Fractalkine/CX3CL1 enhances GABA synaptic activ-ity at serotonin neurons in the rat dorsal raphe nucleus. Neuroscience, 164: 1210-1223, 2009.

Hurst, L. A.; Bunning, R. A.; Couraud, P. O.; Romero, I. A.; Weksler, B. B.; Sharrack, B.; Woodroofe, M. N. Expression of ADAM-17, TIMP-3 and fractalkine in the human adult 
brain endothelial cell line, hCMEC/D3, following pro-inflammatory cytokine treatment. $J$ Neuroimmunol., 210 (1-2): 108-12, 2009.

Irwin, M. R.; Miller, A. H. Depressive disorders and immunity: 20 years of progress and discovery. Brain Behav Immun., 21: 374-383, 2007.

Janssen, D. G. A.; Caniato, R. N.; Verster, J. C.; Baune, B. T. A psychoneuroimmunological review on cytokines involved in antidepressant treatment response. Hum. Psychopharmacol Clin Exp., 25: 201-215, 2010.

Jess, T.; Loftus Jr., E. V.; Velayos, F. S. et al. Risk of intestinal cancer in inflammatory bowel disease: a population-based study from olmsted county, Minnesota. Gastroenterology, 130 (4): 1039-1046, 2006.

Jorgensen, M.; Young, J; Solomon, M. Adjuvant chemotherapy for colorectal cancer: age differences in factors influencing patients' treatment decisions. Patient Prefer Adherence, 7: 827-834, 2013.

Kamińska, J.; Kowalska, M. M.; Nowacki, M. P.; Chwaliński, M. G.; Rysińska, A.; Fuksiewicz M. CRP, TNF-alpha, IL-1ra, IL-6, IL-8 and IL-10 in blood serum of colorectal cancer patients. Pathol Oncol Res, 6 (1): 38-41, 2000.

Klemm, P.; Miller, M.; Fernsler, J. Demands of illness in people treated for colorectal cancer. Oncol Nurs Forum; 27 (4): 633-9, 2000.

Kordatou, Z.; Kountourakis, P.; Papamichael, D. Treatment of older patients with colorectal cancer: a perspective review. Ther Adv Med Oncol, 6 (3): 128-40, 2014. 
Krzystek-Korpacka， M.; Diakowska， D.; Kapturkiewicz， B.; Bębenek, M.; Gamian, A. Profiles of circulating inflammatory cytokines in colorectal cancer (CRC), high cancer risk conditions, and health are distinct. Possible implications for CRC screening and surveillance. Cancer Lett. 337 (1): 107-14, 2013.

Kusahara, D. M.; Peterlini, M. A. S.; Pedreira, M. L. G. Human relations in nursing care towards cancer patients submitted to antineoplastic chemotherapy. Acta Paul Enferm., 21 (1): 77-83, 2008.

Ladecola, C.; Anrather, J. The immunology of stroke: from mechanism to translation. Nat Med, 17: 796-808, 2011.

Landskron, G.; De la Fuente, M.; Thuwajit, P.; Thuwajit, C.; Hermoso, M. A. Chronic inflammation and cytokines in the tumor microenvironment. J Immunol Res, 2014: 2014.

Leonard, B. E. Psychopathology of depression. Drugs Today, 43 (10): 705-16, 2007.

Leonard, B. E. The immune system, depression and the action of antidepressants. Prog Neuropsychopharmacol Biol Psychiatry, 25 (4): 767-80, 2001.

Lieberman, D. A. Clinical practice. Screening for colorectal cancer. N Engl J Med, 361:117987, 2009.

Madden, K.S. Catecholamines, sympathetic innervation, and immunity. Brain, Brain Behav Immun., 17 (Suppl 1): S5-10, 2003. 
Maggi, L.; Scianni, M.; Branchi, I.; D’Andrea, I.; Lauro, C.; Limatola, C. CX(3)CR1 deficiency alters hippocampal-dependent plasticity phenomena blunting the effects of enriched environment. Front Cell Neurosci, 5: 22, 2011.

Matta, A. P. C.; Moreira-Filho, P.F. Sintomas depressivos e ansiedade em pacientes com cefaléia do tipo tensional crônica e episódica. Arq Neuro-Psiquiatria, 61: 991-994, 2003.

Medeiros, M.: Oshima, C. T. F.; Forones, N. M. Depression and Anxiety in Colorectal Cancer Patients. J Gastrointest Canc., 41: 179-184, 2010.

Merendino, R. A.; Di Pasquale, G.; De Luca, F.; Di Pasquale, L.; Ferlazzo, E.; Martino, G.; Palumbo, M. C.; Morabito, F.; Gangemi, S. Involvement of fractalkine and macrophage inflammatory protein-1 alpha in moderate severe depression. Mediators of Inflammation, 13 (3): 205-207, 2004.

Miller, A. H.; Maletic, V.; Raison, C. L.; Inflammation and its discontents: the role of cytokines in the pathophysiology of major depression. Biol. Psychiatry, 65: 732-41, 2009.

Moinpour, C. M.; Triplett, J. S.; McKnight, B.; Lovato, L. C.; Upchurch, C.; Leichman, C. G.; Muggia, F. M.; Tanaka, L.; James, W. A.; Lennard, M.; Meyskens, F. L. Challenges posed by non-random missing quality of life data in an advanced-stage colorectal cancer clinical trial. Psycho-Oncology, 9: 340-354, 2000.

Morikawa, O.; Sakai, N.; Obara, H.; et al. Effects of interferon-alpha, interferon-gamma and cAMP on the transcriptional regulation of the serotonin transporter. Eur. J. Pharmacol, 349: 317-24, 1998. 
Mossner, R.; Heils, A.; Stober, G.; et al. Enhancement of serotonin transporter function by tumor necrosis factor alpha but not by interleukin-6. Neurochem. Int, 33: 251-54, 1998.

Moura, H. V.; Pomerantzeff, P. M. A.; Gomes, W. J. Síndrome da resposta inflamatória sistêmica na circulação extracorpórea: papel das interleucinas. Rev Bras Cir Cardiovasc; 16 (4): 376-87, 2001.

Müller, N.; Ackenheil, M. Psychoneuroimmunology and the cytokine action in the CNS: implications for psychiatric disorders. Prog Neuropsychopharmacol Biol Psychiatry, 22 (1): 1-33, 1998.

Musselman, D. L.; Miller, A. H.; Porter, M. R.; et al. Higher than normal plasma interleukin-6 concentrations in cancer patients with depression: preliminary findings. Am J Psychiatry; 158: 1252-7, 2001.

Nelson. P. J.; Muenchmeier, N. Membrane-anchored chemokine fusion proteins: A novel class of adjuvants for immunotherapy. Oncoimmunology, 2 (11): e26619, 2013.

Nicolussi, A.; Sawada, N.. Quality of Life of patients with colorectal câncer who were receiving complementary therapy. Acta Paulista de Enfermagem, 22 (2): 155-16, 2009.

Ning, Y.; Lenz, H.J. Targeting IL-8 in colorectal cancer. Expert Opin Ther Targets, 13: 491$7,2012$.

Nishida, A.; Hisaoka, K.; Zensho, H.; Uchitomi, Y.; Morinobu, S.; Yamawaki, S. Antidepressant drugs and cytokines in mood disorders. Int Immunopharmacol., 2 (12): 1619-26, 2002. 
O’Brien, S. M.; Scott, L. V.; Dinan, T. G. Cytokines: abnormalities in major depression and implications for pharmacological treatment. Hum Psychopharmacol., 19: 397-403, 2004.

O’Brien, S. M.; Scully, P.; Fitzgerald, P.; Scott, L. V.; Dinan, T. G. Plasma cytokine profiles in depressed patients who fail to respond to selective serotonin reuptake inhibitor therapy. J Psychiatr Res., 41: 326-331, 2007.

Ogino S.; Chan, A. T.; Fuchs, C. S. et al. Molecular pathological epidemiology of colorectal neoplasia: an emerging transdisciplinary andinterdisciplinary field. Gut, 60:397-411, 2011.

Ohta, M.; Tanaka, F.; Yamaguchi, H.; Sadanaga, N.; Inoue, H.; Mori, M. The high expression of Fractalkine results in a better prognosis for colorectal cancer patients. Int J Oncol., 26 (1): 41-7, 2005.

Pacák, K.; Palkovits, M. Stressor Specificity of Central Neuroendocrine Responses: Implications for Stress-Related Disorders. Endocrine Reviews, 22 (4): 502-548, 2001.

Pander, J.; Wessels, J.A.; Gelderblom, H.; van der Straaten, T.; Punt, C.J.; Guchelaar, H.J. Pharmacogenetic interaction analysis for the efficacy of systemic treatment in metastatic colorectal cancer. Ann Oncol, 22:1147-53, 2011.

Pollack, J.; Holm, T.; Cedermark, B.; Attman, D.; Holmstroim, B.; Glimelious, B.; Melgree, A. Late adverse effects of short-course preoperative radiotherapy in rectal cancer. British Journal of Surgery, 93 (12): 1519-25, 2006. 
Ragozzino, D.; Di Angelantonio, S.; Trettel, F.; Bertollini, C.; Maggi, L.; Gross, C.; Charo, I.F.; Limatola, C.; Eusebi, F. Chemokine fractalkine/CX3CL1 nega-tively modulates active glutamatergic synapses in rat hippocampal neurons. J. Neurosci, 26: 10488-10498, 2006.

Ransohoff, R. M.; Benveniste, E. N. Cytokines and the CNS. Taylor \& Francis Group: New York, 2006.

Razavi, D.; Delvaux, N.; Farvacques, C.; Robaye, E. Screening for adjustment disorders and major depressive disorders in cancer patients. British Journal of Psychiatry; 156: 79-83, 1990.

Reed, J. R.; Stone, M. D.; Beadnell, T. C.; Ryu, Y.; Griffin, T. J.; Schwertfeger, K. L. Fibroblast growth factor receptor 1 activation in mammary tumor cells promotes macrophage recruitment in a CX3CL1-dependent manner. PLoS One, 7 (9): e45877, 2012.

Ren, K.; Dubner, R. Interactions between the immune and nervous systems in pain. Nature Medicine, 16 (11): 1267-76, 2010.

Rich, T.; Innominato, P. F.; Boerner, J.; Mormont, M. C.; Iacobelli, S.; Baron, B.; Jasmin, C.; Le'vi, F. Elevated serum cytokines correlated with altered behavior, serum cortisol rhythm, and dampened 24-hour rest-activity patterns in patients with metastatic colorectal cancer. Clinical Cancer Research, 11: 1757-64, 2005.

Rogers, J. T.; Morganti, J. M.; Bachstetter, A. D.; Hudson, C. E.; Peters, M. M.; Grimmig, B. A.; Weeber, E. J.; Bickford, P. C.; Gemma. C. CX3CR1 deficiency leads to impairment of hippocampal cognitive function and synaptic plasticity. J Neurosci, 31: 16241-16250, 2011. 
Ruhé, H. G.; Mason, N. S.; Schene, A. H. Mood is indirectly related to serotonin, norepinephrine and dopamine levels in humans: a meta-analysis of monoamine depletion studies. Mol Psychiatry, 12: p. 331-359, 2007.

Schiepers, O.; Wichers, M. C.; Maes, M. Cytokines and major depression. Prog Neuropsychopharmacol Biol Psychiatry, 29 (2): 201-17, 2005.

Schmidt, C. E.; Bestmann, B.; Kuchler, T.; Longo, W. E.; Kremer, B. Ten year historic cohort of quality of life and sexuality in patients with rectal cancer. Diseases of Colon and Rectum, 48 (3): 483-492, 2005.

Schneider, N. I.; Langner, C. Prognostic stratification of colorectal cancer patients: current perspectives. Cancer Manag Res, 6: 291-300, 2014.

Spath-Schwalbe, E.; Hansen, K.; Schmidt, F.; et al. Acute effects of recombinant human interleukin-6 on endocrine and central nervous sleep functions in healthy men. $J$ Clin Endocrinol Metab, 83: 1573-9, 1998.

Stuart, M. J.; Baune, B. T. Chemokines and chemokine receptors in mood disorders, schizophrenia, and cognitive impairment: a systematic review of biomarker studies. Neuroscience and Biobehavioral Reviews, 42: 93-115, 2014.

Szelényi, J.; Vizi, E. S. The catecholamine-cytokine balance: interaction between the brain and the immune system. Ann N Y Acad Sci, 1113: 311-24, 2007.

Szkaradkiewicz, A.; Marciniak, R.; Chudzicka-Strugała, I.; Wasilewska, A.; Drews, M.; Majewski, P.; Karpiński, T.; Zwoździak, B. Proinflammatory cytokines and IL-10 in 
inflammatory bowel disease and colorectal cancer patients. Arch. Immunol. Ther. Exp., 57, 291-294, 2009.

Tanaka, T. Colorectal carcinogenesis: Review of human and experimental animal studies. $J$ Carcinog., 8: 5, 2009.

Tsunoda, A.; Nakao, K.; Hiratsuka, K.; et al. Anxiety, depression and quality of life in colorectal cancer patients. Int J Clin Oncol, 10 (6): 411-17, 2005.

Ueno, Y.; Tanaka, S.; Chayama, K. Non-polypoid colorectal neoplasms in ulcerative colitis. Gastrointest Endosc Clin N Am, 20: 525-542, 2010.

Umehara, H.; Bloom, E. T.; Okazaki, T.; Nagano, Y.; Yoshie, O.; Imai, T. Fractalkine in vascular biology: from basic research to clinical disease. Arterioscler Thromb Vasc Biol, 24 (1): 34-40, 2004.

Vismari, L.; Alves, G. J.; Palermo-Neto, J. Depression, antidepressants and immune system: a new look to an old problem. Rev Psiq Clín., 35 (5): 196-204, 2008.

Vodermaier, A.; Linden, W.; MacKenzie, R.; Greig, D.; Marshall, C. Disease stage predicts post-diagnosis anxiety and depression only in some types of cancer. Br J Cancer, 105 (12): 1814-7, 2011.

Walling, A. M.; Weeks, J. C.; Kahn, K. L.; Tisnado, D.; Keating, N. L.; Dy, S. M.; Arora, N. K.; Mack, J. W.; Pantoja, P. M.; Malin, J. L. Symptom Prevalence in Lung and Colorectal Cancer Patients. J Pain Symptom Manage, S0885-3924 (14): 342-X, 2014. 
Wedding, U.; Koch, A.; Röhrig, B.; Pientka, L.; Sauer, H.; Höffken, K. Depression and functional impairment independently contribute to decreased quality of life in cancer patients prior to chemotherapy. Acta Oncol; 47: 56-62, 2008.

Wilschut, J. A., Habbema, J. D., Ramsey, S. D. et al. Increased risk of adenomas in individuals with a family history of colorectal cancer: results of a meta-analysis. Cancer Causes Control, 21:2287-93, 2010.

Wrona, D. Neural-immune interactions: an integrative view of the bidirectional relationship between the brain and immune systems. J Neuroimmunol, 172 (1-2): 38-58, 2006.

$\mathrm{Xu}, \mathrm{Y}$.; Pasche, B. TGF- $\beta$ signaling alterations and susceptibility to colorectal cancer. Hum Mol Genet; 15: 14-20, 2007.

Yirmiya, R.; Pollak, Y.; Morag, M.; Reichenberg, A.; Barak, O.; Avitsur, R. et al. Illness, cytokines, and depresión. Ann N Y Acad Sci, 917: 478-87, 2000.

You, Z.; Luo, C.; Zhang, W.; Chen, Y.; He, J.; Zhao, Q.; Zuo, R.; Wu, Y. Pro- and antiinflammatory cytokines expression in rat's brain and spleen exposed to chronic mild stress: Involvement in depression. Behav Brain Res, 225 (1): 135-141, 2011.

Zabora, J.; BrintzenhofeSzoc, K.; Curbow, B.; Hooker, C.; Piantadosi, S. The prevalence of psychological distress by cancer site. Psychooncology, 10(1): 19-28 2001. 
Zhao, G.; Gao, P.; Yang, K. H.; Tian, J. H.; Ma, B. Capecitabine/oxaliplatin as first-line treatment for metastatic colorectal cancer: a meta-analysis. Colorectal Dis, 12 (7): 615$623,2010$.

Zheng, J.; Yang, M.; Shao, J.; Miao, Y.; Han, J.; Du, J. Chemokine receptor CX3CR1 contributes to macrophage survival in tumor metastasis. Mol Cancer, 12 (1): 141, 2013.

Zigmond, A. S.; Snaith, R. P. The Hospital Anxiety and Depression Scale. Acta Psychiatrica Scandinavica, 67: 361-370, 1983.

Zujovic, V.; Schussler, N.; Jourdain, D.; Duverger, D.; Taupin, V. In vivo neutralization of endogenous brain fractalkine increases hippocampal TNF-alpha and 8-isoprostane production induced by intracerebroventricular injection of LPS. J Neuroimmunol, 115 (12): 135-43, 2001. 


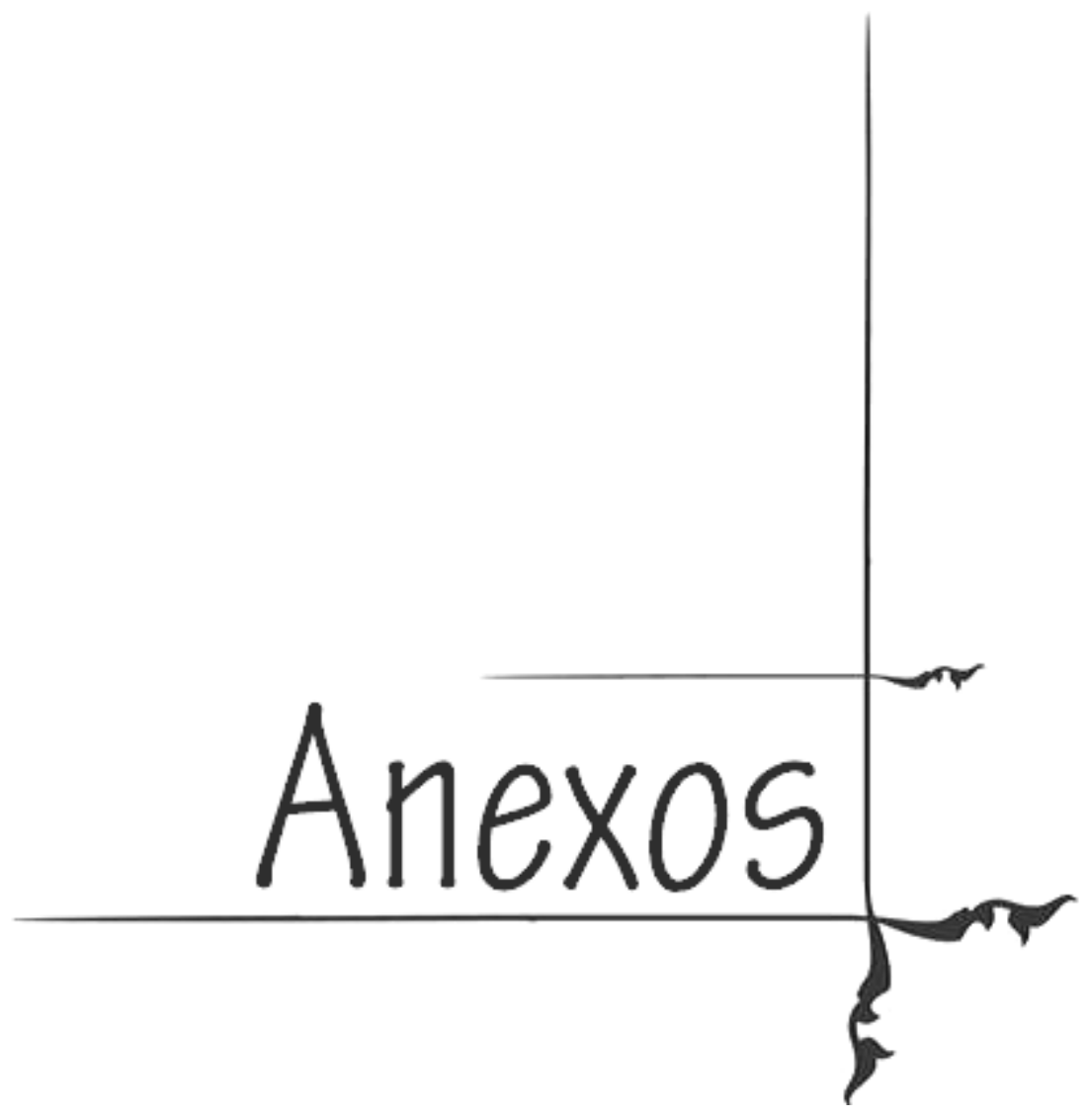


ANEXO 1

\section{Escala Hospitalar de Ansiedade e Depressão}

Marque com um "X" a resposta que melhor corresponder a como você tem se sentido na ÚLTIMA SEMANA. Não é preciso pensar muito em cada questão. As respostas espontâneas têm mais valor do que aquelas em que se pensa muito. Marque apenas uma resposta para cada pergunta.

A 1) Eu me sinto tenso ou contraído:

3 ( ) A maior parte do tempo

2 ( ) Boa parte do tempo

1 ( ) De vez em quando

0 ( ) Nunca

D 2) Eu ainda sinto gosto pelas mesmas coisas de antes:

0 ( ) Sim, do mesmo jeito que antes

1 ( ) Não tanto quanto antes

2 ( ) Só um pouco

3 ( ) Já não sinto mais prazer em nada

A 3) Eu sinto uma espécie de medo, como se alguma coisa ruim fosse acontecer:

3 ( ) Sim, e de um jeito muito forte

2 ( ) Sim, mas não tão forte

1 ( ) Um pouco, mas isso não me preocupa

0 ( ) Não sinto nada disso

D 4) Dou risada e me divirto quando vejo coisas engraçadas:

0 ( ) Do mesmo jeito que antes

1 ( ) Atualmente um pouco menos

2 ( ) Atualmente bem menos

3 ( ) Não consigo mais

A 5) Estou com a cabeça cheia de preocupações:

3 ( ) A maior parte do tempo

2 ( ) Boa parte do tempo

1 ( ) De vez em quando

0 ( ) Raramente

D 6) Consigo sentir prazer quando assisto a um bom programa de televisão, de rádio ou quando leio alguma coisa:

0 ( ) Quase sempre

1 ( ) Várias vezes

2 ( ) Poucas vezes

3 ( ) Quase nunca

A 7) Consigo ficar sentado à vontade e me sentir relaxado:

0 ( ) Sim, quase sempre

1 ( ) Muitas vezes

2 () Poucas vezes

3 ( ) Nunca

D 8) Eu estou lento para pensar e fazer as coisas:

3 ( ) Quase sempre

2 () Muitas vezes

1 ( ) De vez em quando

0 ( ) Nunca

A 9) Eu tenho uma sensação ruim de medo, como um frio na barriga ou um aperto no estômago:

0 ( ) Nunca

1 ( ) De vez em quando

2() Muitas vezes

3 ( ) Quase sempre

D 10) Eu perdi o interesse em cuidar da minha aparência:

3 ( ) Completamente

2 ( ) Não estou mais me cuidando como deveria

1 ( ) Talvez não tanto quanto antes

0 ( ) Me cuido do mesmo jeito que antes

A 11) Eu me sinto inquieto, como se eu não pudesse ficar parado em lugar nenhum:

3 ( ) Sim, demais

2( ) Bastante

1 ( ) Um pouco

0 ( ) Não me sinto assim

D 12) Fico esperando animado as coisas boas que estão por vir:

0 ( ) Do mesmo jeito que antes

1 ( ) Um pouco menos do que antes

2 ( ) Bem menos do que antes

3 ( ) Quase nunca

A 13) De repente, tenho a sensação de entrar em pânico:

3 ( ) A quase todo momento

2 ( ) Várias vezes

1 ( ) De vez em quando

0 ( ) Não sinto isso

D 14) Eu me sinto alegre:

3 ( ) Nunca

2 ( ) Poucas vezes

1 ( ) Muitas vezes

0 ( ) A maior parte do tempo 
ANEXO 2

\section{Termo de Consentimento Livre e Esclarecido (Grupos experimentais)}

Você está sendo convidado (a) a participar da pesquisa "Correlações entre produção de citocinas, depressão e ansiedade em pacientes com câncer colorretal em tratamento diferentes estágios da terapia antitumoral", sob responsabilidade do Enfermeiro Diego Oliveira Miranda, do Departamento de Enfermagem Materno-Infantil e Saúde Pública da Escola de Enfermagem de Ribeirão Preto/USP. Sua participação será muito importante para nós. Caso você não queira participar da pesquisa, seu tratamento será realizado normalmente, sem nenhum prejuízo. Mesmo que aceite participar do estudo, você poderá desistir a qualquer momento, sem que isto interfira com o atendimento ou tratamento que está recebendo. Você não terá nenhum benefício direto ao participar deste estudo, mas estará contribuindo para um melhor entendimento dos efeitos de substâncias produzidas pelo corpo, chamadas citocinas, no desenvolvimento da ansiedade e depressão, sintomas comuns em pacientes com câncer. Essa pesquisa poderá ajudar na formulação de novas e melhores formas de tratamento, melhorando a qualidade de vida de pacientes com câncer colorretal. Não haverá qualquer custo para que você participe deste trabalho, nem haverá nenhuma remuneração pela sua participação. Esta pesquisa não promoverá nenhum risco adicional a você e não interferirá com o seu tratamento. Você receberá uma cópia deste termo, contendo o telefone e o endereço do pesquisador. A qualquer momento, você poderá entrar em contato com ele, podendo tirar dúvidas a respeito do projeto e de sua participação no mesmo. Caso concorde em participar da pesquisa: 1) responderá um questionário sobre depressão e ansiedade, o que levará cerca de 15 minutos; 2) coletaremos uma amostra de sangue de uma veia do seu braço, numa quantidade aproximada de 2 colheres de sopa $(8 \mathrm{ml})$. A amostra de sangue será utilizada para identificarmos a presença de citocinas que possivelmente estão relacionadas com a depressão e ansiedade; 3) dados sobre sua doença e o tratamento serão consultados no seu prontuário médico. A coleta de sangue e do questionário será realizada pelo enfermeiro responsável pela pesquisa, que foi treinado para realizar estas coletas e utilizará material estéril e descartável, de forma a garantir a sua segurança. Caso esteja acompanhado(a), pediremos que o seu acompanhante(s) se retire(m) da sala onde será realizado as coletas por alguns instantes.. Durante a sua participação no estudo, você poderá sentir-se desconfortável em algum momento por lembrar de certos sentimentos. Nesse caso, o pesquisador e a equipe de saúde de onde você está sendo atendido poderão ajudar você. As informações solicitadas nos questionários serão mantidas em segredo, podendo ser divulgadas em eventos científicos e em publicações da área da saúde, sem que você seja identificado.

Agradecemos por sua colaboração.

Ribeirão Preto, de de 20

Participante

Diego Oliveira Miranda

E-mail: imuno@usp.br

Endereço: Escola de Enfermagem de Ribeirão Preto da Universidade de São Paulo

Av. Bandeirantes, 3900 - Campus Universitário - Monte Alegre

Ribeirão Preto - SP.

Tel.: (16) 3602-0538 
ANEXO 2

\section{Termo de Consentimento Livre e Esclarecido (Grupo controle)}

Você está sendo convidado (a) a participar da pesquisa "Correlações entre produção de citocinas, depressão e ansiedade em pacientes com câncer colorretal em diferentes estágios da terapia antitumoral", sob responsabilidade do Enfermeiro Diego Oliveira Miranda, do Departamento de Enfermagem Materno-Infantil e Saúde Pública da Escola de Enfermagem de Ribeirão Preto/USP. Sua participação é importante, mesmo que você não tenha nenhuma doença, pois é necessário comparar os exames dos pacientes com câncer colorretal com os de pessoas saudáveis. Mesmo que aceite participar do estudo, você poderá desistir a qualquer momento, sem que isto lhe cause qualquer problema. Você não terá nenhum benefício direto ao participar deste estudo, mas estará contribuindo para um melhor entendimento dos efeitos de substâncias produzidas pelo corpo, chamadas citocinas, no desenvolvimento da ansiedade e depressão, sintomas comuns em pacientes com câncer. Essa pesquisa poderá ajudar na formulação de novas e melhores formas de tratamento, melhorando a qualidade de vida de pacientes com câncer colorretal. Não haverá qualquer custo para que você participe deste trabalho, nem haverá nenhuma remuneração pela sua participação. Esta pesquisa não lhe promoverá nenhum risco adicional. Você receberá uma cópia deste termo, contendo o telefone e o endereço do pesquisador. A qualquer momento, você poderá entrar em contato com ele, podendo tirar dúvidas a respeito do projeto e de sua participação no mesmo. Caso concorde em participar da pesquisa: 1) responderá um questionário sobre depressão e ansiedade, o que levará cerca de 15 minutos; 2) coletaremos uma amostra de sangue de uma veia do seu braço, numa quantidade aproximada de 2 colheres de sopa $(8 \mathrm{ml})$. A amostra de sangue será utilizada para identificarmos a presença de citocinas que possivelmente estão relacionadas com a depressão e ansiedade. A coleta de sangue e do questionário será realizada pelo enfermeiro responsável pela pesquisa, que foi treinado para realizar estas coletas e utilizará material estéril e descartável, de forma a garantir a sua segurança, e ocorrerão no Laboratório de Genômica e Imunobiologia do Departamento de Enfermagem Materno-Infantil e Saúde Pública da Escola de Enfermagem de Ribeirão Preto-USP, para que você não seja incomodado. Durante a sua participação no estudo, você poderá sentir-se desconfortável em algum momento por lembrar de certos sentimentos relacionados a ansiedade e depressão e no ato da coleta do sangue no seu braço, quando uma leve agulhada poderá causar um pouco de dor e/ou pequenos hematomas locais (manchas roxas). Se você se sentir desconfortável, o pesquisador poderá lhe ajudar. As informações solicitadas nos questionários serão mantidas em segredo, podendo ser divulgadas em eventos científicos e em publicações da área da saúde, sem que você seja identificado.

Agradecemos por sua colaboração.

Ribeirão Preto, de de 20

\section{Participante}

Diego Oliveira Miranda

E-mail: imuno@usp.br

Endereço: Escola de Enfermagem de Ribeirão Preto da Universidade de São Paulo

Av. Bandeirantes, 3900 - Campus Universitário - Monte Alegre

Ribeirão Preto - SP CEP: 14040-902

Tel.: (16) 3602-0538 